\title{
Adolescent and Youth Sexual and Reproductive Health: Charting Directions for a Second Generation of Programming
}

Population Council

Follow this and additional works at: https://knowledgecommons.popcouncil.org/departments_sbsr-pgy How does access to this work benefit you? Let us know!

\section{Recommended Citation}

"Adolescent and Youth Sexual and Reproductive Health: Charting Directions for a Second Generation of Programming." New York: Population Council, 2003. 


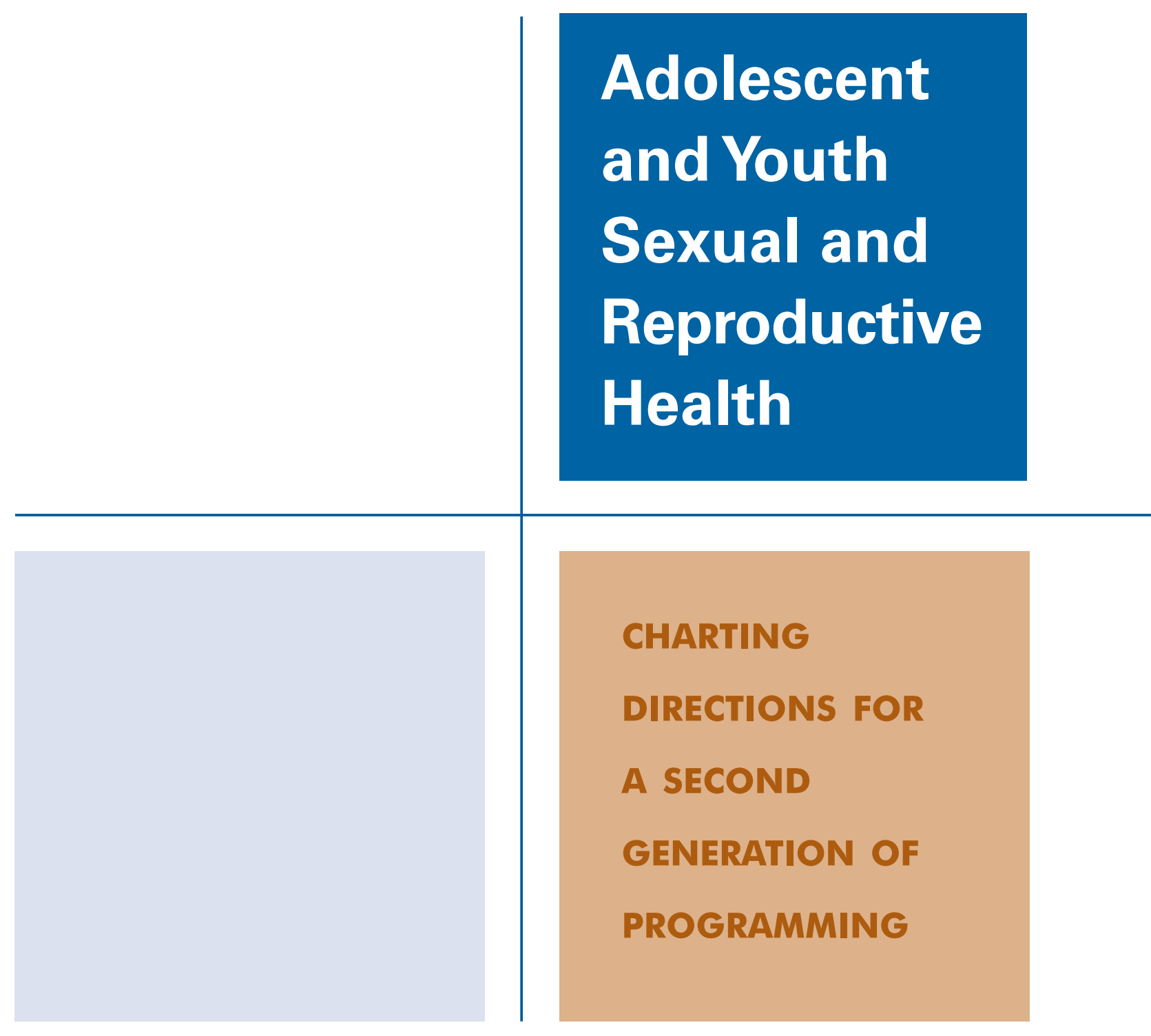

A report on a workshop of the UNFPA in collaboration with the $P$ Population Council 



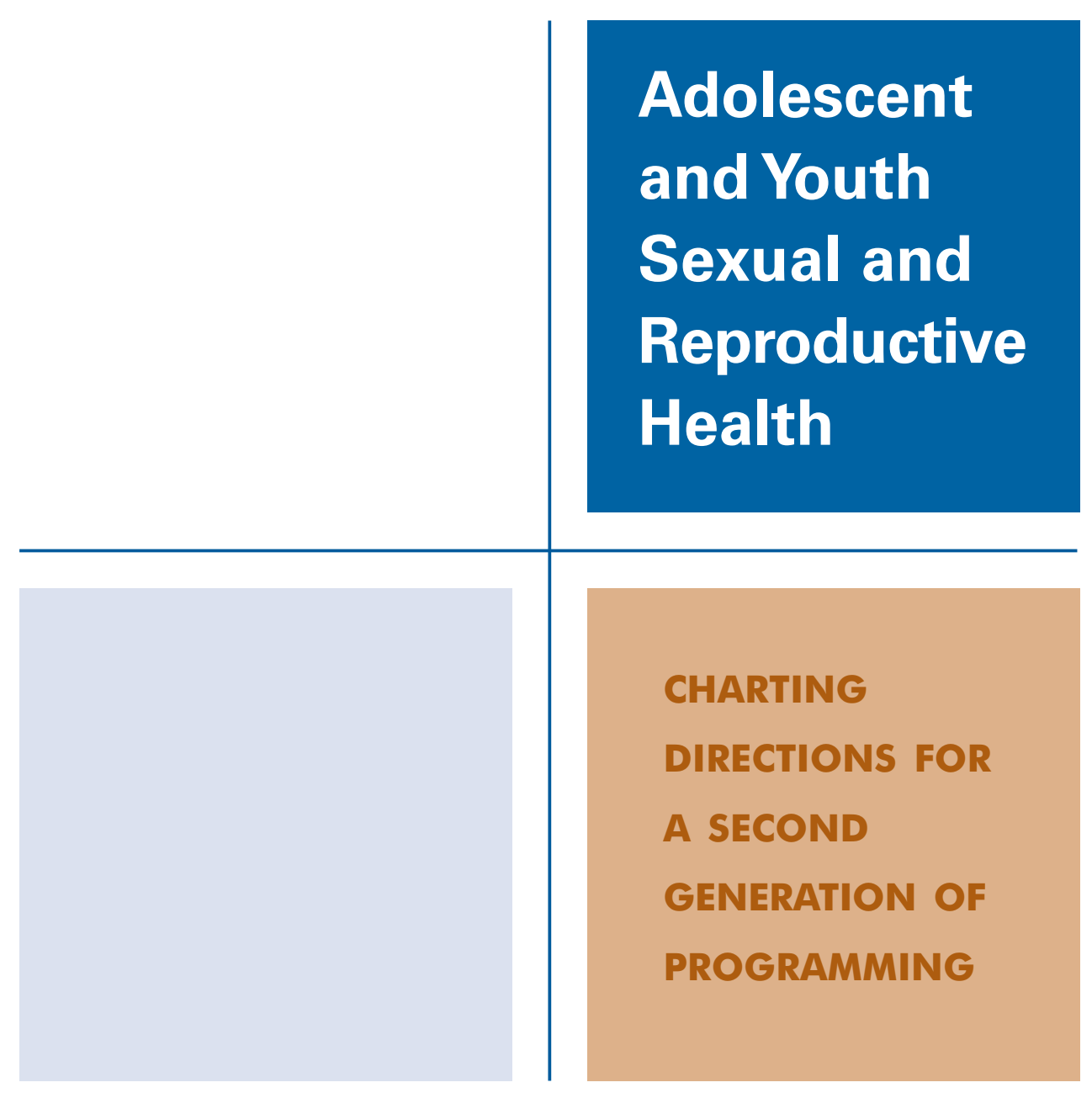

A report on a workshop of the UNFPA in collaboration with the Population Council

1-3 May 2002, New York 


\section{(2) Population Council}

The Population Council is an international, nonprofit, nongovernmental institution that seeks to improve the well-being and reproductive health of current and future generations around the world and to help achieve a humane, equitable, and sustainable balance between people and resources. The Council conducts biomedical, social science, and public health research and helps build research capacities in developing countries. Established in 1952, the Council is governed by an international board of trustees. Its New York headquarters supports a global network of regional and country offices.

Population Council

One Dag Hammarskjold Plaza

New York, New York 10017 USA

212/339-0500; fax 212/755-6052

e-mail: pubinfo@popcouncil.org

http://www.popcouncil.org

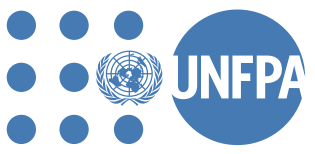

United Nations Population Fund

220 East 42nd Street,

New York, NY 10017, U.S.A.

UNFPA, the United Nations Population Fund, is the world's largest international source of funding for population and reproductive health programs. UNFPA works with governments and nongovernmental organizations in over 140 countries, at their request, and with the support of the international community. UNFPA supports programs that help women, men, and young people plan their families and avoid unwanted pregnancies; undergo pregnancy and childbirth safely; avoid sexually transmitted diseases, including HIV/AIDS; and combat violence against women. Together, these elements promote reproductive health - a state of complete physical, mental, and social well-being in all matters related to the reproductive system. Reproductive health is recognized as a human right, part of the right to health. 


\section{Contents}

Acknowledgments $\quad$ v

Executive Summary 1

Introduction $\quad 5$

Goals and Agenda of the Meeting 6

Opening Session 6

Session 2 A Strategic Approach to Adolescent and Youth Programming:

Learning from the Past and Building for the Future 8

Session 3 Evidence-Based Planning Concepts and Tools for Improved Programming

Session 4 Adolescent Refugees and Internally Displaced Persons

in Emergency Situations

Session 5 The Strategic Value of Education

Session 6 Meeting the Distinctive Needs of Adolescent Girls and Boys

Session 7 Safe Livelihoods for Older Adolescents

Session 8 Working with Married Adolescent Girls

Session 9 Preventing HIV/AIDS Among Adolescent Girls and Boys 



\section{Acknowledgments}

"Adolescent and Youth Sexual and Reproductive Health: Charting Directions for a Second Generation of Programming" was convened at the Population Council's headquarters 1-3 May 2002. The workshop was organized by UNFPA in collaboration with the Population Council. The workshop organizers are grateful for the dedication and tireless efforts of the following individuals: At UNFPA, Laura Laski, Maria Jose Alcala, Lili Koster, Malak Khatib, and the entire adolescent cluster had the vision for this workshop and the wherewithal to bring it to fruition. At the Population Council, Judith Bruce, Carey Meyers, and Rachel Goldberg collaborated closely with UNFPA colleagues on developing the workshop agenda and logistics. The actual workshop would not have been possible without Erica Chong's behind-the-scenes wizardry. Anna Stumpf's technical support was also invaluable. A special thank you goes to the Office Services staff, as well as that of the Office of Publications, at the Population Council.
Emily Arnold served as meeting rapporteur and wrote the original draft of this report. The workshop organizers thank each speaker-Linda Martin, Thoraya Obaid, Mari Simonen, Judith Bruce, Barbara Mensch, Ann McCauley, Susan Adamchak, Nicola Jones, Laura Laski, Carey Meyers, Stan Bernstein, Patricia Guzman, Hally Mahler, Rachel Jones, Allison Pillsbury, Akello Betty Openy, Pamela DeLargy, Cynthia Lloyd, Lkhagvasurengiin Oyun, Noor Mohammad, Delia Barcelona, Martha Brady, Seydou Doumbia, Gary Barker, Alphonsus Ekah, Cecilia Correa, Ziad El-Rifai, Sajeda Amin, Anjali Widge, Lopita Huq, Christine Norton, Jose Garcia Nuñez, Wariara Mbugua, Shanti Conly, George Brown, Mercedes Borrero, France Donnay, G. Ogbaselassie, Geeta Sodhi, Nicole Haberland, Shelley Clark, Angela Stewart-Buchanan, Julitta Onabanjo, and Kunio Waki-for reviewing text attributed to him or her. 



\section{Executive Summary}

The United Nations Population Fund (UNFPA), in collaboration with the Population Council, convened a three-day workshop that took place 1-3 May 2002 at the Population Council's headquarters in New York. The workshop provided an opportunity to review research and programs in the area of adolescent reproductive health and development (the "first generation") and to think critically about key lessons learned from this work as we move forward into the "second generation" of work with this important population.

This report summarizes the presentations and discussions from that workshop. For the purposes of this executive summary, we are gathering key points into two clusters: those that underscore principles of program planning, design, and evaluation, and those that highlight neglected subjects or subgroups on the adolescent agenda. Where possible, reference is made to the sections of the report as well as the background paper* where the reader may find more detailed descriptions.

\section{Program Planning, Design, and Evaluation}

- Facts, not assumptions, are the proper basis for planning effective programs. A review of the first generation of programming revealed that key target groups were often missed, and some less vulnerable subgroups (older adolescents who were in school, for example) were reached instead with interventions, because unfounded assumptions were made about the lives and needs of adolescents. This phenomenon can be prevented in the future if the necessary background research and analysis are done. (See Sessions 2 and 3 of this report and Chapters 4b, 5, 6, and 9 in the background paper.)

- Adolescents are a diverse group, and their diversity must be considered when planning programs. The first generation of adolescent programming tended to homogenize the adolescent or youth experience. The workshop repeatedly emphasized the importance of diversifying the information base and designing strategies tailored to the distinctive needs of adolescents based on their:

- Age

- Gender

- Marital status

- Schooling status

- Residence

- Living arrangements (with one, two, or no parents)

- Migration status

The research reported on at the workshop suggested that there are often dramatic contrasts in the needs, vulnerabilities, and capacities of adolescents. For example, a strategy such as youth centers-which have not always been safe spaces for girls and have tended to be selective of older boys' participationmay be suitable for reaching out-ofschool boys ages 15-19 but may miss or even be inimical to the needs of out-ofschool girls ages 10-14.

A gender-differentiated strategy is essential to program planning and is timely as we evaluate the effectiveness of the four most popular first-generation programs: youth centers, youthfriendly services, family-life education, and peer-education programs.

\footnotetext{
* Copies of the background paper, "Adolescent and youth sexual and reproductive health: Charting directions for a second generation of programming-Background document" (New York: Population Council, 2003), may be obtained by contacting Erica Chong at echong@popcouncil.org.
} 
- Boys and girls have very different experiences, particularly during puberty. In many places, girls' mobility, schooling, and selfesteem become starkly differentiated from those of their brothers, and girls' lives become constrained. Where girls have few places to gather away from their families outside of school-if school is even an option-boys have more mobility and gathering places although the activities undertaken in those spaces and their peer relations may be far from safe. Understanding the separate experiences of boys and girls and taking them into account when planning programs is necessary for the development of sound programs. (See Session 4 of this report and Chapters 2, 3, and $4 a$ in the background paper.)

- To assure acceptability and sustainability, local stakeholders and community leaders must be involved in program planning. When relevant data are available on a target population, it is useful to review this information with local stakeholders. In some instances, they will actually be surprised by the information. The process of questioning the assumptions of stakeholders is valuable in and of itself. Furthermore, their input in interpreting information and developing plans fosters a sense of community ownership of a project and may spark interest in doing original research to further understand the situation of adolescents in a community. (See Session 2 of this report.)

- Monitoring and evaluation should not be afterthoughts - research, observation, and documentation are processes that should be built into programs from the beginning. Data collection and interpretation during the planning phase will help inform later monitoring and evaluation phases and are an essential part of program design. Because program- ming for adolescents is still so new, a diagnostic phase wherein information is gathered about and from key stakeholders is essential. It is almost impossible to monitor or evaluate a program competently when it is finished if there has not been a regular process of observation and documentation. (See Session 3 of this report and Chapter 2 in the background paper.)

- Program plans should take into account the role that new social and economic options might play in assisting adolescent boys and girls in achieving good sexual and reproductive health. Whereas the first generation of interventions focused heavily on health, information provision, and occasionally the provision of health technologies, information and technology are not always effective in giving adolescents-especially girlsthe tools to forge better life paths. Because the health, social, and economic aspects of adolescents' lives are closely integrated, participants repeatedly affirmed the importance of working across sectors and at the community level. To do this competently, participants acknowledged the importance of working outside the health sector and forming partnerships with organizations that have expertise in community mobilization, livelihoods development, or other types of interventions that build skills. (See Sessions 2 and 7 of this report.)

\section{New Program Content and Neglected Subgroups}

The conventional wisdom of the first generation of adolescent programming had the strength of building on what was already known about reaching adolescents - yet most of what was known was learned in Western settings. Thus, key subgroups were often neglected, and content outside the normal purview of health interventions often was not explored. 
- In many countries - particularly throughout West Africa and South Asia-the majority of sexually active adolescent girls are married. The first generation of adolescent programs focused primarily on unmarried adolescents who often were in school. The entry points they employed for reaching this population-family-life education programs in schools, youth centers, peer education approaches, and youth-friendly clinicsfocused on contraception and occasionally STI prevention, and were largely out of the reach of married adolescent girls. There was much discussion about a variety of interventions that could target married adolescents, including how to redirect antenatal pregnancy care and after-care programs to make sure that married adolescents, their partners, and other gatekeepers in their lives were included. Parallel interventions will be necessary to reduce the proportion of girls married while adolescents through community-based strategies for changing the norms around early marriage.

In some settings, deferring marriage is especially urgent as some married adolescents are differentially vulnerable to HIV infection (see below). (See Sessions 8 and 9 of this report, and Chapter 10 in the background paper.)

\section{- Refugees and internally displaced} populations often include a significant proportion of adolescents. Workshop participants portrayed the experience of displaced adolescents as adding a layer of complexity to program planning. Adolescent refugee groups are detrimentally affected by the lack of community infrastructure, limited opportunities to attend school, limited or no health care, increased vulnerability to physical and sexual abuse, and the absence of positive role models.

Participants agreed that diagnostic research-especially strategies that include adolescents themselves - is of great value and that special attention should be given to gender dimensions. The programs described outlined ways of including adolescents at each stage-planning, implementation, and even evaluation-resulting in increased credibility and the creation of peer leaders. (See Session 4 of this report.)

- In many countries, particularly in subSaharan Africa, adolescent girls are potentially doubly affected by HIV because they are vulnerable to infection and often act as caregivers. Adolescents, especially girls, are often vulnerable to HIV infection because of their lack of social status and their economic vulnerability. In some instances, adolescents are responsible for providing care to HIV-positive kin, a role that may turn them into de facto heads of household. This situation may increase their own susceptibility to infection if they begin seeking income from unsafe sources (e.g., sex work) or engage in exchanging sex for food or school fees.

In some settings in sub-Saharan Africa there is emerging evidence that early marriage brings increased vulnerability to HIV infection. A married adolescent may have frequent sexual relations with her husband who is often older and sexually experienced. She is also often subject to pressure to bear a child soon after marriage. (See Session 9 of this report and Chapter 10 in the background paper.)

- Investments in education are linked to a myriad of positive long-term effects, yet access to high-quality education-especially for girls - continues to pose a barrier to progress. Workshop participants discussed how the challenge of getting girls into school can be overcome through any number of 
incentives (e.g., subsidies to parents, building dormitories, building village schools).

The discussion returned several times to the importance of gender training for teachers, as there is increasing evidence that in some places teachers are not only insensitive to gender issues but may actually harass girls themselves. (See Session 5 of this report and Chapters $4 a$ and $4 b$ in the background paper.)

- Effective sexuality and reproductive health education requires participation and support of stakeholders at all levels (e.g., national, local, teacher, parent, and student). Evidence from a UNFPA-supported project in Mongolia illustrated the results of strong community support and sense of ownership in a comprehensive and gendersensitive sexuality education curriculum. (See Session 5 of this report.)

- Boys' special needs must not be overlooked when planning programs for adolescents. While boys enjoy greater mobility relative to their female peers, they may congregate in unsafe spaces and engage in risky activities. Boy-dominated spaces may also expose boys to social content or gender norms that do not promote respect for girls and women. Programming for adolescent boys can address their specific needs, as well as foster long-term change by working to alter gender norms through addressing the male sense of entitlement, questioning practices of violence against sexual partners, and attempting to eliminate homophobia, which leads some boys to exaggerate their masculinity in negative ways (e.g., machismo, use of force in sexual relationships, and unwillingness to participate in nurturing, childcare, and domestic activities). (See Session 6 of this report and Chapters 6 and 7 in the background paper.)
- Boys have distinctive needs with regard to reproductive health information and access to services. Boys generally know less than their female peers about reproductive health, yet they have a hard time acknowledging their need for information. At the same time, boys are more likely to be sexually active. Improving boys' access to positive mentors, as well as their comfort at youth-friendly health services (which boys often consider girls' spaces), were discussed as possible areas for intervention. (See Session 6 of this report and Chapters 6 and 7 in the background paper.)

\section{- Livelihood programs may serve the dual} purpose of offering adolescents opportunities to attain a better standard of living, become self-motivated, and achieve mobility while reducing risky behavior that often results from social and economic vulnerability. The livelihoods approach recognizes the fluid links between the economic and noneconomic aspects of adolescent lives, and the association of livelihoods with education and reproductive health. Many participants emphasized the importance of looking at livelihoods as a gradient of skills and acknowledging the relationship, particularly for adolescents, between social, productive, and reproductive issues. Mention was again made of the value of working with partners outside of the health sector who have a track record and expertise in financial literacy, savings, employment/ vocational training, and micro-finance.

In some settings, the workplace (including training areas) may offer an appropriate and attractive venue for sexual and reproductive health programming. (See Session 7 of this report and Chapter 8 in the background paper.) 


\section{Introduction}

\section{Thoraya Obaid, Executive Director, UNFPA}

Adolescence is recognized as the stage of life in which individuals establish their own identities and prepare to become adults. For many young people across the world, however, the notion of adolescence as a time of self-development under safe and healthy conditions could not be further from their reach. Millions live in poverty or other difficult circumstances, with little access to knowledge and resources.

Both girls and boys face many challenges and pressures. For boys, adolescence can be a time for expanded participation in community and public life. Girls, however, may experience intensifying restrictions, with their freedom of mobility severely limited. In addition, pressures derived from traditional gender roles restrict girls' future prospects to roles as wives and mothers, giving them little say about their own aspirations and hopes. Boys also face multiple and parallel societal and peer pressures, as they may be encouraged to be risk-takers and to demonstrate their manhood through aggressive behavior, thereby putting themselves and others in unsafe situations.

Today, adolescents, and adolescent girls in particular, are the age group among whom $\mathrm{HIV}$ infection is most rapidly spreading. Every year millions of young girls face unwanted and early pregnancy, unsafe abortion, and sexually transmitted infections (STIs). Obstetric fistulae-a largely ignored condition that results from internal ruptures in girls who are simply too young to be bearing children-are yet another horrific reproductive health outcome that affects adolescent girls. The world over, the majority of adolescents, married and unmarried, in school and out of school, lack access to sexual and reproductive health information, education, and services, and therefore lack the means by which to prevent unwanted outcomes that can have a detrimental impact on their futures.

Investing in young people is a top priority of the United Nations Population Fund (UNFPA), which is guided by the goals of the International Conference on Population and Development (ICPD) and its five-year review of progress (ICPD+5). The ICPD Programme of Action gave special attention to the conditions of adolescents, including the health of pregnant adolescents, HIV prevention, gender equality in the areas of reproductive health and rights, and their impact on poverty reduction and development trends in general. These goals highlight the stake young people have in the development process and the general relationship between health and development.

Recognizing the crucial challenges adolescents face today, UNFPA and the Population Council joined forces to examine the latest trends and evidence on program approaches that address adolescent sexual and reproductive health. While many challenges remain, the evidence is demonstrating that investing in young people is the best intervention now and for the long term. In short, investing in young people is important for a host of ethical, human rights, gender, and economic reasons. Simply stated it makes good sense. This report summarizes the presentations and open discussions from a three-day meeting entitled "Adolescent and Youth Sexual and Reproductive Health: Charting Directions for a Second Generation of Programming" that took place in New York 1-3 May 2002.

Lessons learned from the experiences of UNFPA and its partners are critical for a second generation of programming in adolescent reproductive health. Because the world is different for girls than it is for boys, program approaches must account for this. Programs 
that work with governments, nongovernmental organizations (NGOs), and others using a multisectoral approach and that differentiate the needs of adolescent girls and boys must also provide more attention to married adolescents (who are treated as adults when they are still girls and boys). Addressing these issues requires change at multiple levels, including service delivery, funding priorities, community resources and environments, and adult behavior and attitudes.

While there is a long way to go in developing effective program approaches to meet adolescent and youth priorities, UNFPA is ready to address the challenge of the second generation.

\section{Goals and Agenda of the Meeting}

UNFPA invited key staff to attend the workshop, which was organized by UNFPA in collaboration with the Population Council, to map new directions for a second generation of adolescent programming. The objectives were twofold:

- to provide state-of-the-art research findings and evidence-based guidance for adolescent programming strategies, building on a review of the first generation of adolescent sexual and reproductive health programs; and

- to provide input for future programming in adolescent sexual and reproductive health.

Each of the nine sessions was structured around the latest research and program findings on adolescent sexual and reproductive health. Presentations were made by experts from UNFPA, the Population Council, and others. The themes of the sessions were:

- lessons garnered from the first generation of programs;

- data analysis and evaluation approaches;
- the importance of tailoring programs to the diversity of adolescents;

- the strategic value of education in supporting adolescent social development and reproductive health;

- creating safe and supportive spaces for girls;

- creating safe and supportive spaces for boys;

- the challenges in developing safe and appropriate livelihood programs;

- the emerging challenges of preventing HIV/AIDS; and

- the neglected social and health needs of married adolescent girls (and their partners).

Each theme emphasized the importance of building on development and rights-based agendas, developing and drawing on data and systematically evaluating field experiences, employing multisectoral approaches where appropriate, explicitly addressing diversity and gender-related inequalities, and finding partner organizations with complementary skills.

This report is organized around the summaries of each session. Subsequent sections are divided into two parts: a summary of the presentations and a summary of the discussions that followed the presentations.

The workshop was followed by an internal session at UNFPA headquarters to discuss the implications of the meeting for UNFPA programming and to generate initial recommendations (available on request).

\section{Opening Session}

The opening session was chaired by Mari Simonen, Director of the Technical Support Division at UNFPA. Linda Martin, President of the Population Council, opened the workshop by welcoming the participants and noting the Council's pleasure in collaborating with UNFPA. 
She expressed her admiration for UNFPA and the leadership role it has played and will continue to play in shaping the experience of the one billion young people who are beginning their reproductive and productive lives. Acknowledging the limited resources available for this work, she highlighted the importance of evaluating previous efforts and identifying the most cost-effective approaches. She concluded by observing that UNFPA is uniquely positioned to make an extraordinary contribution, given its ability to reach across multiple development sectors, and bring about large-scale change.

Thoraya Obaid, Executive Director of UNFPA, then offered opening remarks on behalf of UNFPA. She noted that the workshop came at a timely moment-it took place one week before the United Nations Special Session on Children, which reviewed progress in implementing the UN Convention on the Rights of the Child (CRC). (The CRC protects children up through age 18 so that the vast majority of adolescents fall under its protection.)

Dr. Obaid offered statistics on the vulnerability of adolescents. Each year, 10-11 million teenage marriages take place in less-developed countries (excluding China) and 15 million adolescent girls get pregnant; in addition, approximately 7,000 adolescents are infected by HIV every day. Adolescent programs can break the cycle of poverty and encourage youth empowerment and involvement in civil life. Dr. Obaid asserted that by offering adolescents appropriate social support and access to sexual and reproductive health programs, UNFPA can unleash their potential, particularly that of young girls. Young people must become agents of their own empowerment.

Ms. Simonen reviewed the goals of the workshop. She noted that UNFPA has been engaged in adolescent programs for the past three decades, supporting family-life education, sexuality education in schools, peer education, multipurpose youth centers, youthfriendly services, and youth participation.
Because adolescents are an increasingly high-priority focus of UNFPA, it is essential to review past experience. Ms. Simonen envisioned a future agenda that, while continuing the commitment to reproductive health information and services, is expanded to include an adolescent social and economic development agenda. She underscored the high value that UNFPA has placed on understanding the distinctive needs of girls and boys, incorporating gender concerns into mainstream programming, and including young people themselves in programming decisions.

Ms. Simonen framed the challenges of the workshop-from UNFPA's perspectiveas follows:

- What can UNFPA learn from its experiences? How can it develop a knowledge base that is useable and accessible to program developers?

- How can adolescent programs strengthen their monitoring and evaluation? What are the key issues to consider at different stages of programming, such as during planning, implementation, and the monitoring and evaluation stages?

- What are the key populations adolescent programs should consider? Addressing the diversity of adolescents is a challenge, given differences in rural/urban residential status, marital status, gender, age, and war-affected or refugee status.

- How can adolescent programs consider sustainability in the design stage?

- How can UNFPA advocate for the adolescent health, social, and economic agenda in other forums? Linking adolescent concerns to larger development agendas should remain a key goal. 


\section{Session 2-A Strategic Approach to Adolescent and Youth Programming: Learning from the Past and Building for the Future}

This session, chaired by Elizabeth Lule, Population Advisor at the World Bank, examined the lessons learned from the predominant approaches to adolescent sexual and reproductive health during the first generation of programs, and introduced alternative intervention models that thus far comprise the second generation.

\section{The First Generation: Lessons Learned from Predominant Approaches to Adolescent Sexual and Reproductive Health}

Barbara Mensch of the Population Council reviewed the experience of youth centers, drawing on data from three research studies conducted in Ghana, Kenya, and Zimbabwe with the Planned Parenthood Association of Ghana, the Family Planning Association of Kenya, and the Zimbabwe National Family Planning Council. Typically, youth multipurpose centers have been structured around recreational activities, libraries, and career counseling. These activities are complemented by the provision of reproductive health information and services.

Dr. Mensch reported that use of reproductive health information and services attached to the youth centers was low-in some settings, only two or three young people might be seen in a day. In many cases, the hours and the days of operation were not convenient. She also noted that the high-profile association of family planning efforts and adolescent programs effectively stigmatized the centers (in some cases, signs saying "Family Planning Association” were prominently displayed). Users of the youth centers were not the youngest adolescents, and often were not teenagers at all. The clientele tended to be older-the average ages of attendees were 18 years in Ghana, 21 in Zimbabwe, and 24 in Kenya (in Ghana and Zimbabwe over 40 percent of those using reproductive health services were over age 24). Centers in Kenya and Zimbabwe were also much more likely to attract males than females. While staff volunteers were often knowledgeable about reproductive health issues, their attitudes prevented them from providing nonjudgmental information about sexuality and protection from STIs and pregnancy. Staff were also only variably observant of the need to protect the confidentiality of their young clients.

Ann McCauley of the Population Council summarized the lessons learned from several decades of experience of family-life education programs, noting that UNFPA has a long history of supporting these programs. She framed her remarks by explaining that the local context often plays a significant role in determining the relative success or weakness of such programs; she therefore urged the audience to look carefully at each situation and not to generalize. (Dr. McCauley based her conclusions on current Horizons program schoolbased programs in Mexico, South Africa, and Thailand and on the extensive literature on these types of programs.)

The strength of family-life education is its broad acceptance within the community, particularly where the community has been engaged before the introduction of family-life education and involved in creating the curriculum. However, this same acceptability strategy has a weakness; the content generated can be overly general and diluted. Many programs lack a precise focus on sexual and reproductive health and give little, if any, attention to issues such as male dominance of females and sexual decisionmaking, and child-parent negotiations regarding marriage. These power dimensions must be dealt with if young people 
are to adopt voluntary, informed, and safe sexual and reproductive behaviors and values. While these interventions were initiated with, and were most suited to, in-school youth, their benefits can be multiplied if messages are spread beyond the school, such as through youth scouts, youth clubs, and so forth.

In some settings, family-life education has become politicized, which has resulted in programs covering a very limited agenda. For example, some programs emphasize total abstinence as a protection strategy for young people, even in settings where a substantial proportion are sexually active and potentially without protection. Family-life education primarily reaches only those in school, and has rarely been successful in reaching young people who are married, out of school, older, or in difficult living circumstances (e.g., migrants and orphans). Recent improvements to familylife education programs have resulted in life skills programs that go beyond providing information to teaching young people negotiation, planning, and refusal skills through role plays and practice. Although family-life education is a good first step and has gained wide policy support, it is not a sufficient program approach on its own. It is, however, a valuable part of an overall strategy to reach young people, because such programs increase knowledge and communication about reproductive health issues among adults, such as teachers and administrators, as well as among youth.

Susan Adamchak of the Population Council made a presentation on peer education and youth-friendly services, in which she pointed to strengths that could be exploited in the next generation of programs. She based her comments on a report prepared by the Frontiers program in the context of HIV prevention and the Population Council's experience in this area. Peer-education programs employ trained peers similar in age, background, and often gender to effect change in populations with similar characteristics. This approach has had some success with "hard-to-reach" youth. Research has revealed that friends are the primary source of sexual and reproductive health information for young people, and that peer education can create changes in environment, affect attitudes, provide information, and increase acceptance of programs.

Peer educators require selective recruitment, training, supervision, and ongoing support. Peer educators "age out," howeverthey naturally have a high turnover and typically a short term of service-which can be addressed by careful selection, use of contractual arrangements, good support, consistent reinforcement, and compensation and other rewards. In addition, peer educators can handle only a limited number of queries and are not equipped to handle issues of negotiation and self-esteem and other more difficultand, sadly, common-situations such as sexual coercion and sexual abuse by adults.

Discussions with peer educators may open the door on these difficult subjects, but a cadre of better-trained, perhaps older, counselors are needed to deal with them. Peer educators may not be able to provide intensive and sustained efforts to promote behavior change in large groups, but they can be part of a good initiating strategy.

Dr. Adamchak stated that peer education should not be a stand-alone activity, rather it should be packaged with complementary elements to build a comprehensive approach to adolescent programming. While peer education has a clear and positive impact on the peer promoters themselves, it may not be the most efficient way to reach young people.

It is unclear whether school- or peerbased programming is more effective. While community-based peer programs do change behavior, the greatest effects are often seen among in-school youth. As yet it has been difficult to determine whether the impact is the 
result of peer programs or other activities. Similarly, there may be differential effects by gender, age, and marital status, but few studies have reported on these distinctions.

There is some evidence of success of peer programs with hard-to-reach populations such as street children, sex workers, and out-ofschool young people. Such programs may also prove effective in reaching young married women, although this population is likely to start accessing health facilities as they begin childbearing, and as such will have a point of contact with health providers then. Further evaluation of peer-education programs is required to better understand their effectiveness.

Dr. Adamchak went on to discuss youthfriendly services, that is, developing service procedures within the context of existing family planning and reproductive health programs, so that young people seeking specific services (mostly contraceptive, but sometimes STI services) feel welcomed. Such services have been available through both private- and public-sector partners, and have not been limited to the clinical setting - some function within schools and youth outreach programs.

While many young people clearly are in need of better information and services, thus far youth-friendly services have not reached this population. Such services, centered in traditionally "adult" clinical circumstances, are often viewed as inappropriate sources of care by young people. In a parallel manner, providers, whose central experiences are with adults, may be uncomfortable about the legality and moral responsibility of serving young people.

Also, because existing reproductive health and family planning clinics have been geographically based on the needs of adults, they are not always geographically accessible to young people, who are not only on the move but may want to be served outside of their communities. Dr. Adamchak emphasized the need for future youth-friendly service programs to combine a number of strategiesincluding outreach and community awareness in addition to clinics - and the possibility of reaching young people in nonclinical venues where they congregate.

When considering the accessibility of services for young people, time is perhaps of greater importance than geography. Most public clinics operate on fixed schedules that are not compatible with the hours or days when schools are not in session, or when young people are not working.

\section{The Second Generation of Adolescent and Youth Programming}

Judith Bruce of the Population Council outlined the three main tasks of moving forward to a second generation of programming.

- Advocates of adolescent sexual and reproductive health programs must make a stronger case to other sectors for investing in adolescents.

- Programs must be responsive to the internal diversity* of adolescents. Without such attention to important segments of the adolescent world, programs will be unable to attract committed participation by young people themselves or yield sustainable results.

- Because adolescents are not simply "younger adults" or "older children" the success and effectiveness of interventions for adolescents must be defined in the context of their transition to adulthood, and the

\footnotetext{
* Paying attention to diversity involves considering age, sex, marital status, education level, urban/rural
} residence, number of parents who live at home, and so forth. 
knowledge, capacities, and opportunities that they need and will benefit from-as measured by their selfperception, informed decisionmaking, strengthened personal assets, positive peer and mentoring relationships, social mobility, power in negotiation, and acquisition of skills.

Ms. Bruce proposed that program planners build the case for investments in adolescents on the UN Convention on the Rights of the Child, which offers both protections and rights to children up to the age 18 -including the right to information they need to manage their health and lives. While programs should be based on development-oriented, rightsaffirming principles, a rights-based framework does not obviate the need for close analysis and provision of evidence of success.

Emphasizing diversity as a theme, Ms. Bruce not only highlighted the stark differences among adolescents of different ages, genders, and schooling and marital status, among other factors, but also suggested that program content must be diversified.

She queried the impact of the first generation of programming (e.g., family-life education, youth centers, peer education, and youth-friendly services) in combination with more standard interventions, on significant subsets of adolescents, including those 10-14 years old, boys and girls, those in and out of school, and those who are unmarried and married.

Programs that are based on clear evidence and that include evaluation increase our ability to make the case for investment in adolescents. The first generation of programs was introduced quickly, but was not well-evaluated. Better program evaluation enables planners to engage other sectors and design programs with more refined and achievable objectives. The evidence-based approach is best served by a process that has an authentic diagnostic phase and some budget flexibility so that lessons learned in the first analytic phases and pilot demonstrations can be used to change program design over time.

Key partners in adolescent programs include young people, their parents, and nongovernmental and governmental agencies with talents and interests outside the health sector. Participation of adolescents as peer counselors, while desirable, must be examined critically-young people may not be able to be drawn in en masse as volunteers, and they often age out of programs. Involving adolescents in the design of programs and in the early phases of implementation is perhaps easier to accomplish than giving them responsibility for "managing" programs and finding the resources to sustain them. Obviously, it is best if parents and other gatekeepers can be made into program allies; however, in cases where they cannot, programs must be prepared to act on their behalf in order to protect young people, especially girls. Finally, the other sectors are clearly important partners, as many programs will have content that falls outside of the comfortable, better-known health arena. Forming strategic alliances with partners in other social and economic development fields (some perhaps who have limited experience working with young people but who are willing to learn) may be the best way to diversify program content.

Finally, many of the sexual and reproductive health outcomes we are seeking for adolescents may not become visible within three to five years; benchmarks such as delayed marriage, avoidance of infection with HIV, spacing of children, better marital or partner communication, and so forth can indeed be achieved, but most likely will take place five or even ten years later. Socio-cultural and gender transformations are required. Sustained behavioral changes take place over time. Thus we must define benchmarks that are attain- 
able within relatively short time frames and that represent goods in and of themselves, but also lead logically to desirable health and demographic changes. Such benchmarks include (and are mentioned in documents such as the (RC) increased knowledge, selfesteem, social mobility, retention in school, and positive peer relationships.

Nicola Jones of UNFPA shared some insights into how the adolescent agenda fits into UNFPA's strategic directions. She referred to a recently completed exercise that indicates how UNFPA can best pursue the objectives laid out in the ICPD agenda. The review included an analysis of how sexual and reproductive health is best achieved, revealing the interdependence of social, economic, and health factors. Poor reproductive health knowledge and behaviors in young people can lock them, particularly girls, into a cycle of poverty. The best and perhaps the last opportunity for programs to effectively intervene in this cycle is during adolescence.

UNFPA is re-examining the meaning of adolescence across societies. There is a fair amount of diversity between cultures regarding how the transition to adulthood is viewed and the "tasks" of transition that are assigned to boys and girls. Ms. Jones emphasized that, in the past, there had been no investigation of what adolescent lives look like in different domains and a resulting homogenization of their identities. UNFPA will adopt a more culturally sensitive and evidence-based approach and likely substantially increase the investment it makes in qualitative and quantitative data collection. It will use its standing and extensive array of programs to place adolescence high on national and international agendas and to bring NGOs and youth organizations to the table.

Laura Laski of the UNFPA Adolescent Cluster discussed the potential of evidencebased programming at UNFPA. She stated that a more rigorous use of data to fine-tune adolescent programs and policies would likely foster better results. Without substantial new expenditures, existing data could be used to identify the most vulnerable adolescents, important gender differences among adolescents, and how these differences may affect their knowledge, behaviors, and, ultimately, their health. Much, though certainly not all, of this data is "free" and readily available. Overall, the costs of mounting programs not based on evidence outweigh the additional expenditures necessary to conduct a sound diagnostic phase.

Data are also vital to advocacy. In order to conduct a compelling dialogue with policymakers and the media and to influence public opinion, UNFPA must collect information about and from young people. Also vital to the success of the next generation of programs is the expansion of partnerships with other sectors, as addressing adolescent social issues requires change at multiple levels and the involvement of the education, sports, military, and employment sectors, among others. UNFPA's current emphasis on youth participation should be expanded to include other aspects of development, particularly in the area of livelihoods and the creation of safe spaces for girls.

\section{Summary of Discussions}

Most of the discussion revolved around the comments made about youth centers, familylife education, peer education, and youthfriendly services.

It was generally accepted that youth centers were often underutilized because of inconvenient hours, the stigma of a close association with family planning, and the attitudes of staff toward young people in general but often, especially, toward young unmarried girls. Some in the audience felt successful youth centers were possible. It was suggested that centers 
diversify their program content to include more activities that girls like or that some centers be reserved for girls alone to encourage more use and less stigma. One participant said, "I don't want to hear the sentence that youth centers don't work," to which one of the presenters responded, "And I don't want to hear that youth centers do work. Perhaps we can all agree that for each strategy we need to specify for whom they work and for whom they don't work; that is really the issue."

The audience generally agreed with the assessment given of family-life education and discussed those who were missed by that approach, which is centered in schools. Further, the audience lamented how family-life education programs diluted information on sexual and reproductive health, and therefore reduced their utility. At the same time, audience members acknowledged the usefulness of the family-life education approach in building community support for sexual health programs for young people.

There was a fair amount of enthusiasm for peer-education programs and their potential—perhaps not fully realized-to address issues concerning social norms, self-esteem, and negotiation. Most discussants confirmed that peer educators required ongoing supervision, training, and that their period of service was often too short. Questions raised concerned whether peer education as a strategy was equally applicable to different sets of peers, for example, younger adolescents, girls, and boys; which peers speak to whom; and whether age-, gender-, and marital and schooling status-specific peer-education programs should be developed. A suggestion was made that innovative evaluation methodologies such as network analysis should be employed to assess the efficacy of peer education for different groups, and with respect to different subjects, such as its impact on prevention of HIV infection.

\section{Session 3-Evidence-Based Planning Concepts and Tools for Improved Programming}

This session, chaired by France Donnay of the Reproductive Health Branch,Technical Support Division, UNFPA, examined ways in which data can be used for program planning, monitoring, and advocacy. It reviewed data sources and data gaps, and, in some instances, proposed ways of filling them.

Carey Meyers of the Population Council and Stan Bernstein of UNFPA opened the session with a discussion of how to use existing data - in this case, Demographic and Health Survey (DHS) data-to get a clear picture of adolescent lives. The Population Council has compiled and tabulated data on adolescents in 47 countries. For each country, information is organized in as many as 14 tables to reveal-often in surprising terms — facts about adolescents with regard to schooling and work status, living arrangements, sexual activity, childbearing, and other reproductive health indicators. Close attention is given to disaggregating data by age, gender, and marital and schooling status. Ms. Meyers pointed out that even the most preliminary cut of data for a given country may challenge existing assumptions about young people. The DHS data show, for example, that young people in many countries-particularly older adolescents-are not in school, that a substantial proportion of younger adolescents may be living with neither parent, and that the majority of sexually active adolescent girls in lessdeveloped countries (excluding China) are married. Ms. Meyers and Mr. Bernstein argued that investing money (often not a large amount) and time at the outset of a project to develop a specific problem-based strategy will save money in the long term and in many cases may obviate the need for primary data collection. 
Key aspects of young people that program planners should examine include gender, age, urban/rural status, living arrangements (i.e., living with both parents, with one parent, or with no parent), and schooling, work, and marital status. In addition to variations in these key aspects, young people's lives are also likely to vary in terms of personal resources, such as social networks, access to schooling, and the potential protection of parents. Data sources can include national censuses, UNICEF's Multiple Indicator Cluster Surveys, existing situation analyses, Living Standards Measurement Surveys, other project-level research, and DHS (in particular "Facts about adolescents from the Demographic and Health Survey," published by the Population Council).

Mr. Bernstein emphasized the need to include strong monitoring and evaluation components, most easily generated for programs that have built their strategies on data. He suggested designing projects that target the actual documented needs of particular populations and allow for flexibility. In this, he hearkened back to the first session's question, "Do youth centers work?" and concluded that they neither work nor do not work. Rather, the question must be completed: "Do youth centers work for out-of-school boys ages 15-19? Do they work for in-school girls ages 10-14?"

Through specification alone, many programs would be able to develop a simple monitoring plan and determine whether they are accomplishing their objectives. Without such specificity, however, it is possible that what is achieved - even if it is vaguely measurablewill not be able to be attributed to the program, and program managers will not know whether a particular strategy worked for a specific audience. Specificity of problem statement allows the program to identify mismatches, such as finding and observing older boys rather than the younger girls the program intended to reach.
In many instances, monitoring a project requires little more than common sense. For example, routine record-keeping that collects information on the gender, marital and schooling status, and living arrangements of program beneficiaries can increase the program's reach and effectiveness.

Rita Badiani of UNFPA Mozambique and Pathfinder International gave an example of how to use relatively limited resources to do better intervention targeting. The program she described consisted of three interconnected approaches to young people-school-based, community-based, and clinic-based approaches - that involved out-of-school peer educators, parents, young people, teachers, counselors, and also employed community radio programs. Initially, the program made use of qualitative and quantitative data to assess efficacy, drawing on a survey of students to determine where they had accurate knowledge and where they did not.

The initial cut did not disaggregate by gender, which Ms. Badiani recognized as a drawback. She expressed a desire to learn more about girl-to-girl and boy-to-boy communication because she suspects that peer education without a gender component might fall short of the mark.

An interesting adjunct study focused on out-of-school young people, examining their understanding of sexuality, sexual and reproductive health decisionmaking, and use of leisure time. Ms. Badiani looks forward to taking another look at the data and the program procedures to determine who is making use of program services and whether the program has been reaching the most vulnerable populations. There is great demand for services, which is one measure of success. After a relatively short period of program experimentation and planning on a small scale, the program will be extended to three provinces in the country. 


\section{Summary of Discussions}

Most of the discussions reaffirmed the principles laid out by the presenters but gave special attention to programs that are not collecting evidence and credible documentation. As one participant said, "Programs that are not documented miss the opportunity to share lessons learned with others in a meaningful way." Another participant observed that information collection is not necessarily a lengthy process and actually allows a program to maintain its relevance and flexibility so that it can quickly identify groups that, despite good planning, are not being served.

Examples were shared of programs that have been evaluated at such a general level (e.g., the program is well-used) that the program planners as well as their sponsors were unclear about which parts of their efforts needed strengthening and/or replication and scaling up.

Special attention in the discussion was given to youth participation. Existing data should be supplemented by interviews with young people in focus groups selected by age, gender, marital status, and so forth. Such information can only enhance programs and help to avoid miscalculated strategies and mismatches.

\section{Session 4-Adolescent Refugees and Internally Displaced Persons in Emergency Situations}

This session, chaired by Mercedes Borrero, Assistant Representative, UNFPA Colombia, reviewed evidence-based examples from Egypt, Kosovo, Sierra Leone, Tanzania, Uganda, and Zambia of sexual and reproductive health programs developed for adolescent refugees and internally displaced persons in emergency situations.

\section{The Health of Adolescent Refugees Project}

Hally Mahler of Family Health International described the Health of Adolescent Refugees Project, a two-year intervention to improve the general and reproductive health of adolescent refugees, supported by UNFPA and the United Nations Refugee Agency in Egypt, Uganda, and Zambia. Refugee adolescents face multiple challenges, including lack of services, increased vulnerability to sexual violence, language and cultural barriers, and lack of positive role models.

The project established Girl Guide units in refugee sites that offer a reproductive and general health curriculum through Girl Guides, who serve as peer educators and employ a "learning by doing" methodology. A particularly innovative feature of this project is the way in which links are established to existing clinical services. Girl Guides peer educators act as "consultants" to adult health providers, advising them on how to make the mix and interpersonal dimensions of health services more adolescent-friendly. Health providers work with Girl Guide groups, teaching sections on reproductive health, serving as technical backup to the peer educators, and gaining exposure to young people and their health needs.

The project evaluation emphasized a variety of informational and social objectives. The assessment revealed that participant refugee girls (both Girl Guides and the girls they reach) retained accurate information, and the Girl Guides themselves increased their self-confidence, developed a sense of group identity, enjoyed a sense of fun away from the stress of everyday life, and, most importantly, developed a relationship with a mentoring, caring adult female. In effect, the project created a "space" for refugee girls heretofore lacking.

Future programming attention will be given to ensuring that as many materials as 
possible are available in local languages and that they are adapted for use with illiterate adolescent boys and girls. While girls will remain a primary focus of the project, a strategy for boys will be developed, as they also need information on sexual and reproductive health and positive adult male role models.

\section{Reproductive Health Knowledge, Attitudes, and Practices Survey of Refugee Adolescents in the Kigoma Region of Tanzania: Findings and Lessons Learned*}

Rachel Jones of the International Rescue Committee reported findings from a cross-sectional knowledge, attitudes, and practices survey conducted among refugee adolescents in the Kigoma region of Tanzania, funded by the Women's Commission for Refugee Women and Children. The survey was carried out by 100 community health workers, many of whom were refugees themselves, who received two days of training to administer the interview in village settings. A sample of 1,500 adolescents was interviewed through random selection of 25 percent of the village, and within those villages 7 percent of the households participated. The team interviewed one boy and one girl in each household. The youngest adolescents (ages 10-13) were least well-represented (and most difficult to find and interview), and the sample contained more male than female adolescents. The mean age of respondents was 16 years.

There were significant differences between adolescent boys and girls regarding knowledge of and education in reproductive health, family planning, and HIV. Only 13 percent of unmarried adolescents surveyed had heard of reproductive health or family planning, but awareness was greater among females (17 percent) than males (8 percent) pointing to the need for distinct strategies for reaching boys and girls. It was also clear that information and behavior were not necessarily linked, as those with HIV/AIDS knowledge did not necessarily practice safe behaviors.

Ms. Jones and colleagues affirmed the value of including adolescents in early stages of study design, involving them in generating questions at every stage, and finding new and better ways to monitor gender balance throughout the process.

\section{Promoting the Protection and Capacity of Adolescent Refugees in Kosovo, Sierra Leone, and Uganda}

Allison Pillsbury of the Women's Commission for Refugee Women and Children described participatory adolescent research projects undertaken in Kosovo, Sierra Leone, and Uganda that work with adolescents in a holistic manner, ensuring that the many dimensions of adolescent life are represented. An initial review of programs and policies relating to war-affected adolescents was conducted across five sectors of adolescent life: education, livelihoods, health, psychosocial dimensions, and protection. That research, published in "Untapped potential: Adolescents affected by armed conflict," a report published by the commission, found that adolescents in waraffected areas are more likely to be recruited into armed conflict, suffer sexual violence and related health problems, be exposed to HIV/AIDS and STIs as a result of coercion or economic disadvantage, be required to work for pay and therefore run the risk of exploitation, and miss out on educational opportunities.

The commission trained a diverse group of war-affected adolescents to serve as

\footnotetext{
* Rachel Jones credits Sandra Krause, Naomi Nyitambe, Millicent Obaso, Margaret Mukabana, and Michelle Thompson as collaborators.

${ }^{\dagger}$ Allison Pillsbury credits Jane Lowicki of the Women's Commission for Refugee Women and Children as a collaborator.
} 
researchers under the guidance of adult research advisors and in collaboration with youth coordination groups. The research sought to answer the question, "What are the main problems for adolescents in our country today, and what are some solutions?" Their work underscored the importance of giving attention to gender and the diversity of adolescent needs. It also made clear that solutions to problems in one sector could not be attained without work in the other sectors.

Training refugee adolescents in research is time-intensive and requires ongoing advocacy with program planners and funders to ensure their commitment to follow up the research with appropriate implementation plans. Funding for research and project implementation ideally should be received and planned in tandem to assure implementation of research findings. Ms. Pillsbury acknowledged that data collection efforts are most fruitful when they can report specific information about the needs of different age and gender groups.

\section{Precious Resources: Adolescents in the Reconstruction of Sierra Leone}

Akello Betty Openy, an adolescent researcher and activist, described the project carried out by the commission in the Gulu district of northern Uganda. She and her peers interviewed over 2,000 adolescents and adults in northern Uganda and generated several suggestions, such as including information on sexual and reproductive health and HIV in the school curriculum, improving access to information and emergency support through formal and nonformal education, and increasing social and psychosocial services for adolescents. Empowering girls through education and skills training was seen as a key strategy to assist them in avoiding sexual abuse and exploitation based on their economic vulnerability as refugees.
Gulu Youth for Action, a youth group founded by Ms. Openy and other researchers following their participation in the Women's Commission project, faces challenges in implementing its program plans, which include fully involving girls in programming, getting parents to allow their girls to participate, and finding sufficient personnel and funding resources.

\section{Summary of Discussions}

The discussion was brief as time was short but there was great enthusiasm for the systematic and participatory way in which the research and action programs described were carried out. The issue that received the most attention was the need for agencies to be comfortable with research, willing to fund research, or willing, by their program cycles, to allow for a diagnostic phase on which to base implementation plans. Discussion also included comments on the need for improved indicators to monitor and evaluate gender balance in adolescent initiatives.

\section{Session 5-The Strategic Value of Education}

\section{Importance of Investment in Early and High-Quality Schooling of Girls}

This session, chaired by Shanti Conly, Senior Technical Advisor for Youth Reproductive Health, USAID, focused on the broadest policy arguments for increased investment in schooling; the influence, direct or indirect, of schooling experience on reproductive health; the features of successful in-school and out-ofschool programs; and family-life education both in and out of the school setting.

Cynthia Lloyd of the Population Council opened the session by highlighting new perspectives on schooling for girls based on recent Council research. Lloyd looked at four factors associated with promoting the schooling of girls: the social and economic benefits 
of investing in girls, the decision to enroll, the decision to drop out, and policies to promote girls' schooling.

There are tangible social and economic benefits to investing in girls. Summarizing the work of T. Paul Schultz, the highest economic rate of returns to investments in basic schooling comes from investing in those who have the least schooling (girls), rather than raising the level of education of those who have more (boys). Schultz's work also indicates that differential social externalities are potentially affected by investments in girls' education, such as improved child survival, better child health, greater children's schooling, and lower fertility. Lloyd then examined the decision to enroll in three key domains: proximity to schools (especially in places where there are concerns about girls being away from home), parental concerns about school quality, and the timing of school entry. Looking at data from Pakistan on the role of proximity, in cases where a school was present in the village, girls were more likely to attend ( 35 percent not in school versus 52 percent in school). The importance of school quality (which was measured by a teacher's residence within the village) was also found to have a significant impact on schooling for girls (40 percent of girls attended school when the teacher resided outside of the village versus 75 percent who attended when the teacher resided within the village). In Pakistan, teachers who are women have more difficulty traveling, therefore those who resided within the village were more likely to provide high-quality instruction.

The US literature demonstrates that young people learn better and achieve more years of schooling when they begin their education early, and classes consisting of young people in one age group are easier to teach. Although flexible policies on school starting age do allow more young people to attend school, there is some concern about the quality of instruction in schools with these policies. Factors such as nutritional status, distance to school, school fees, and domestic responsibilities have been cited in research on delayed enrollment.

Examples of research on factors affecting dropout were drawn from research in Egypt and Kenya. Data from Egypt found that dropout rates for girls in preparatory school were six times greater for those attending double-shift schools than for those attending single-shift schools. In Kenya, girls were significantly less likely to drop out when teachers took their academic abilities seriously (as measured by teachers' viewing math skills as important for girls). The Kenya data also led the Council to question conventional wisdom about the effect of pregnancy on school dropout rates. Among girls who left school, only 1 percent said that pregnancy was the cause. Furthermore, girls attending schools with a more gender-neutral atmosphere were less likely to engage in premarital sex. Taken together, the evidence from Kenya raises interesting questions about cause and effect: Do schools that foster a protective environment for girls encourage a delay in sex, making pregnancy an unlikely cause of school dropout? Further research should be done to investigate the relationship of gender treatment and pregnancy to school dropout. Dr. Lloyd recommended several policy strategies to promote schooling for girls:

- subsidies to parents to encourage them to send their girls to school are likely to increase enrollment rates, provided legislators also ensure a high quality of education in the schools themselves;

- infrastructural investments; and

- gender training for teachers. 


\section{Sexual and Reproductive Health Education: The Experience of UNFPA in Mongolia}

Lkhagvasurengiin Oyun, a health educator on leave from the National Health Development Center at the Ministry of Health in Mongolia, spoke on the experience of creating sexual and reproductive health education programs in schools in Mongolia.* Dr. Oyun shared three strengths and two challenges of the UNFPAsupported program in Mongolia. Among its strengths, the program is implemented nationally by the government, which has mandated that sexual education be taught to every enrolled child in grades 3-10 in all schools. It took a great deal of advocacy work on the part of UNFPA and early program leaders within the Ministry of Health (with support from colleagues within Margaret Sanger Center International) to achieve this policy. Meetings were held with the ministers of Education, Health, and Finance to gain their support and plan the curriculum. Second, UNFPA encouraged investment in local capacity building as well as a locally developed curriculum. Technical advice was provided by Margaret Sanger Center International. The curriculum developed considered age-specific developmental issues. For example, students learned about their bodies from early ages, and by grades 9-10 they received instruction on sexual relationships, self-respect, and communication, including safer sex and condom use.

The overarching goal of the program was comprehensive sexuality education. In keeping with this goal, the curriculum addressed gender inequality as well as other sexuality-related topics, another strength of the program. During its implementation, however, the program encountered two major challenges: a limited number of hours in which to provide sexuality education and "pulled topics" from the curriculum. Only 4.5 hours per year were allotted by the government to teach sexual education, a far from adequate amount of time, while experts recommend more hours. In addition to the low number of mandated hours, the Ministry of Education gave school instructors the choice to teach the following topics: sexual harassment, child abuse, decisionmaking (including sexual decisionmaking), domestic violence, human sexual response, and the responsibilities of each partner in a relationship. Although teachers received training on these topics, they were not mandated to teach them in their classrooms. In response to the positive response by students, teachers, and parents, however, the government is expected to increase the number of hours of required sexuality instruction after a planned review in 2003.

\section{Life Skills for Out-of-School Girls}

Noor Mohammad of UNFPA Bangladesh made a presentation on life-skills training for out-ofschool married girls. Life-skills training enables individuals to develop positive skills in order to deal effectively with the demands and challenges of everyday life.

According to the DHS fact sheets on Bangladesh, 88 percent of adolescents live in rural areas, and 70 percent of girls ages 15-19 do not go to school. The literacy and education levels for this group are among the lowest in the Asian region, and reflect tremendous gender disparities. Overall, 50 percent of adolescents ages 10-19 are illiterate. The mean age of marriage for girls is 18 years while for boys it is 27 , reflecting an average spousal age difference of 9 years. Alarming new trends in adolescent health include an increase in pre-

\footnotetext{
* The Mongolian sexual and reproductive health education project supported by UNFPA was featured in the most recent issue (no. 12) of Quality/Calidad/Qualitépublished by the Population Council. The introduction to the issue was co-authored by Delia Barcelona and Laura Laski of UNFPA. To obtain a copy, e-mail Michelle Skaer at mskaer@popcouncil.org.
} 
marital sex, a rise in the proportion of teenage mothers, and an increasing number of adolescent girls in the labor market. The life-skills training project was aimed at out-of-school married adolescent girls, one of the most vulnerable populations in Bangladesh.

The project had two objectives: to increase awareness and understanding of adolescent girls' reproductive health needs among themselves and those around them; and to develop and disseminate knowledge, create innovative approaches, and increase institutional capacity to implement program interventions appropriate to adolescent girls.

The project was implemented in partnership with the Department of Youth

Development under the Ministry of Youth and Sports. Working at the grassroots level with local youth centers, the program developed local capacity in adolescent reproductive health by providing training to peer leaders within the centers. These peer leaders, in turn, reached out to married adolescent girls, forming support groups and teaching them about adolescent reproductive health.

Through the support groups, the project introduced married adolescents to health service providers to facilitate accessibility to health services. The Department of Youth

Development also sponsored skills training at the youth centers; married adolescent girls received priority for this training and also opportunities to participate in loan schemes. After acquiring a particular set of skills (e.g., sewing, poultry raising, block-batik) girls could apply for loans of up to Tk25,000 (approximately US\$500) to undertake an income-generating project.

The idea that married adolescent girls should have access to new opportunities did not meet with immediate acceptance. Thus, advocacy was an important ingredient at all levels. Project workers found that it was difficult to gain access to married adolescent girls, so they formed partnerships with local gatekeepers to overcome this barrier. The community was sensitized to the rights of these girls and their capacities, and special efforts were made to reach husbands, parents, teachers, and community and religious leaders. By influencing the environment in addition to influencing the girls themselves, it has been possible to build more support for the reproductive health of married adolescent girls.

The numbers of community members who support the project are increasing. Furthermore, UNFPA anticipates that the adolescent groups - two groups in each upazilla (the subdistrict level) consisting of at least 30 members in each - will become change agents for the society.

\section{Summary of Discussions}

The discussions emphasized that investments in girls' education effect other important changes in addition to benefits for girls, including improved child survival, better child health, greater investments in children's schooling and the next generation, and lower fertility.

Participants observed that any number of incentives seemed to work, ranging from subsidies to parents for girls' schooling to infrastructural investments, such as building dormitories for girls that would ensure a separate and safe space for them. The discussion returned several times to the importance of gender training for teachers, as there is increasing evidence that in some places teachers are not only insensitive to gender issues but may actually harass girls themselves.

The discussion of the project for out-ofschool married adolescent girls touched on two subjects important to the workshop overall. The first was the importance of developing strong community support for out-of-school initiatives in general and especially with regard to socially isolated groups such as 
married adolescents. The process used to increase the schooling opportunities for married adolescents, in this case, paralleled a finding discussed later in the workshop regarding the importance of understanding that married adolescent girls are more isolated and often far more disadvantaged than their unmarried counterparts.

As schools often are not supportive of girls, participants discussed steps that could be taken to make schools safer and more supportive. Participants from the Population Council mentioned that they are working with the Ministry of Education in Kenya to design and evaluate a teacher-training program that will make both male and female teachers more aware of girls' needs and the often negatively gendered environment of schools.

The second generation of adolescent programming must focus on building programs that consider the distinctive needs of boys and girls, incorporating gender issues into lifeskills education and encouraging behavior change. Clearly, providing information alone to adolescents — as valuable as it is - does not automatically change their choices.

\section{Session 6-Meeting the Distinctive Needs of Adolescent Girls and Boys}

This two-part session, chaired by George Brown, Associate Director of Health Equity at the Rockefeller Foundation, discussed the challenges of creating safe, supportive spaces for boys and girls. Girls often have, relative to boys, few or no spaces of their own. Boys, on the other hand, may have their own spaces, but these spaces might not be safe in the sense that they expose boys to social content or gender norms that do not promote respect and equality. In chairing the session, Dr. Brown observed that we can't improve girls' social, economic, and health choices, including their reproductive health outcomes, without parallel efforts to offer boys different views of what it means to be a man and without undertaking policy and program initiatives that encourage young men to function as supportive partners and peers.

\section{Increasing Girls' Mobility and Social Empowerment}

Martha Brady of the Population Council presented information on an intervention research project aimed at creating safe spaces for adolescent girls that is being piloted in upper Egypt. This initiative is emblematic of a broader "Safe Spaces" effort that the Council and partner organizations are fostering. The Safe Spaces concept emphasizes the need to create spaces for girls where they:

- can find a supportive peer network (girls' peer networks often shrink at puberty and in general are much smaller than those of boys);

- can find adult female mentors, apart from teachers and mothers, who can provide them with a sense of connectedness and serve as positive role models;

- are given the opportunity to acquire new and valued skills (including functional literacy), participate in team sports and have leadership roles, acquire rudimentary economic knowledge, and find support for future livelihood efforts; and

- can freely discuss sensitive subjects such as harmful traditional practices, male/female relationships, and sexual and reproductive health.

The Egyptian project-called Ishraq (which means "enlightenment")—-has been mounted in partnership with the Egyptian ministries of Education and Youth and Sports and NGO partners Save the Children, the Centre for Development and Population Activities, and 
CARITAS. The project is being carried out in Minya, a traditional governorate in Upper Egypt where girls' schooling opportunities are limited and early marriage is endemic.

Ishraq is aimed at out-of-school girls ages 13-15. It offers them opportunities to "learn, play, and grow," with the longer-term objective of enhancing their ability to participate in key decisions regarding their future productive and reproductive lives. In the diagnostic phase of the project, existing quantitative data, a new survey, and some qualitative data were compiled to paint a picture of girls' time use, workloads, social activities, and aspirations and expectations, as well as the perspectives of their parents, boys, and other gatekeepers regarding activities appropriate to adolescent girls. Of particular importance was documentation of girls' social networks and mobility patterns. For example, data were collected on acceptable places for girls to go, how girls move within the community, circumstances that hinder the mobility of married and unmarried girls, and existing community norms regarding girls' opportunities.

The intervention offers girls -in cohorts of up to 50 in three villages - training in literacy and numeracy, opportunities to engage in sports and other physical activities, cultural awareness, opportunities for community service, and training in basic economic and problem-solving skills. Keeping girls engaged requires ongoing relationships with parents and community gatekeepers. In addition, the attitudes and behaviors of brothers are being examined to determine why public harassment of girls is so prevalent so that future interventions can be designed for boys who, while protective of their own sisters, often create discomfort for girls (i.e, other boys' sisters) in public places.

Using a research and evaluation strategy that employs a baseline process documentation, monitoring evaluation, and a post-test, the project will track its effectiveness. Of interest will be improvements in girls' safe mobility, time use (reductions in their unfair workload at home), attitudes toward marriage, relationships with family members and peers, sense of self-efficacy and self-expression, and the evolving attitudes of parents and boys toward girls' exercise of rights and capacities. The project is oversubscribedthat is, more girls would like to participate than can be accommodated - which indicates a high level of community acceptance. However, the project promoters have learned that there are many issues that require continued attention and monitoring. For example, some parents need to be persuaded of the utility of the project, and they need to be assured that the safety and dignity of their daughters will be protected. In addition, early engagement is a problem; project staff have been working with parents and future husbands to convince them to permit engaged girls to continue participating in the project.

Creating a space for girls means paying close attention to the social, familial, and logistical factors that can impede girls' participation, for example, choosing an appropriate time of day for project activities, ensuring safe and secure transportation to and from home in order to protect girls' reputations, and engaging gatekeepers and parents early to win approval and community acceptance. Key strategies have remained flexible and have been designed to enhance girls' participation.

Seydou Doumbia, Country Director for the Population Council in Mali, reported on the findings of a collaborative study undertaken by the Ministry of Youth and Sports and UNFPA to learn more about the lives of adolescent girls in Bamako and the implementation of the ministry's national youth policy. In Mali, as in many other countries, girls are not formally barred from participating in sports activities, although levels of girls' and boys' sports par- 
ticipation differ widely. With UNFPA support and technical assistance from the Population Council, the ministry diagnosed obstacles to girls' participation. The study was also designed to generate a base of information on attitudes regarding gender, suitable age for marriage, disparities in educational experience and attainment, work, social networks, mobility, sports participation, and reproductive health knowledge.

The study found that both boys and girls must seek parental permission to go out, but that boys got permission much more easily than did girls. Further, girls' mobility tended to be closely linked to domestic responsibilitiesthat is, they were able to go places when their families wanted them to, but, for example, they did not frequent youth centers. Approximately 40 percent of girls reported being harassed often (harassment was defined on a continuum of behaviors including being yelled at or heckled by boys and men while in the streets). When boys were queried about their behavior, they stated that they harassed girls because they thought it was "funny." Boys also said they heckled girls because girls should not be in the street, they were wearing provocative clothing, or they liked to be teased.

The finding from this study that affirmed the need for creating spaces for girls was boys had a much higher level of social affiliation than girls. Only 27 percent of girls belonged to a group versus 62 percent of boys. Only 31 percent of girls (versus 88 percent of boys) had been involved in a sports activity in the preceding week. Both boys and girls reported working for pay, with boys employed mainly in small trade and girls working to provide childcare in the household or involved in small trade or food production. Interestingly, in Mali girls tend to be remunerated for their work more often than boys, because boys are usually in apprenticeships during this period of their lives.
Based on the findings of the study, the Ministry of Youth and Sports is developing a strategy to enhance girls' participation in ministry-sponsored activities. Special efforts are being made to address the location of program activities, recruit females to lead activities, and reconsider the scheduling of events to accommodate girls.

\section{Engaging Boys: Knowing Their Needs, Changing Their Norms, and Supporting Safe and Positive Sexual and Reproductive Health Behavior}

Gary Barker of Instituto Promundo in Brazil made a presentation on how to reduce the dichotomy between boys' and girls' worlds. He suggested it was possible, at least in the Brazilian context, to bring them together while addressing gender issues and sexual and reproductive health concerns. Adolescent boys should be targeted with sexual and reproductive health programming for the following reasons: boys have their own needs; they are often open and eager to discuss their sexual relationships; and, crucially, because gender roles are rehearsed during adolescence, working with boys is also good for girls.

Boys are much more likely to be found outside the home than are girls, making it easy to engage them in programs. Adolescent boys are a diverse group; for programming purposes it is important to consider whether they are married, unmarried, in school, out of school, and whether their sex partners are female or other young men (between 1 and 16 percent of young men in various contexts around the world admit they have had sexual experiences with other men). Despite the internal heterogeneity of boys' sexual worlds, they share similarities that distinguish them from adolescent girls. In most regions, boys engage in sexual activity at a younger age than girls. They are as or more frequently misinformed about issues of sexual and 
reproductive health than girls, yet they find it difficult to admit their lack of knowledge. HIV/AIDS prevention campaigns can increase condom use among boys, but this use is inconsistent, owing to lack of communication with partners and gender scripts that have tended to stigmatize condom use for both males and females. Adolescent fathers (a phenomenon that is rare worldwide but common in the Western hemisphere) may face social pressure to leave school and find work. In addition, young men, like young women, are ill-prepared for parenthood, and boys who are fathers need special support and skills. Finally, connecting boys to health services is a challenge as boys tend to view reproductive health as a female concern and clinics as "female spaces."

While programming for adolescent boys can address specific needs, long-term change will require altering gender norms-including the male sense of entitlement, the acceptance of violence against sexual partners, and homophobia, which leads some boys to exaggerate their masculinity in negative ways (e.g., machismo, use of force in sexual relationships, and unwillingness to participate in nurturing, childcare, and domestic activities).

Socially, boys are often lonely and isolated. Efforts to reach them are usually welcomed and can enable them to function as allies in pursuit of girls' and women's reproductive health, as well as primary agents of their own.

\section{Youth Perspectives on the Gender- Specific Needs of Adolescents*}

Cecilia Correa of the Foundation for the Study and Investigation of Women in Argentina was the final presenter and offered what she had learned from young people themselves about their sexual and reproductive health.

Much of what she said affirmed Dr. Barker's perception of young males' view of services as essentially designed for and relevant to females. In Argentina, sex education and family-life education are not provided through the schools, so most adolescents discuss sexual matters with peers who may or may not have accurate information.

Perceptions of acceptable sexual behaviors for adolescent boys and girls in Argentina vary dramatically. Males are expected to dominate females and be the sexual decisionmakers, while females are expected to be passive, which is considered a measure of their femininity. The active expression of virility through sexual intercourse is thought to be a key component of masculinity, and young men are under substantial pressure to initiate sexual behaviors early. Adolescent girls, on the other hand, are encouraged to preserve their virginity until marriage. Getting clear information from girls and boys can prove quite difficult as adolescent boys tend to exaggerate the number of their sexual partners, while girls often understate their sexual experience.

Opening the door for exchange of information is encumbered by fear and ignorance. So that they can appear masculine, boys may be reluctant to ask questions regarding their sexuality. Program methods that allow for "anonymous" questions to be submitted may be helpful in this regard. In spite of these challenges, Ms. Correa observed that young people in Argentina could be engaged, were enthusiastic, and were probably the best sources of information for each other-that is, peer-education programs for girls reached girls and programs for boys reached boys with accurate information in places that allowed for discussion of underlying fears about sex roles and power issues - and that peer-education programs were vital. Mass media can also play a role by frankly confronting the underlying construction of male/female imagery.

\footnotetext{
* Cecilia Correa credits Laura Pagani and Claudio Vera as collaborators.
} 


\section{Summary of Discussions}

The discussions centered on the best ways to create spaces for adolescent girls that protect them over both the short and long term. Clearly, in highly traditional settings where marriageability is key to girls' survival, and early marriage is common, any activity directed at adolescent girls must protect their reputations and preserve their marriageability. As such, interventions must have gatekeepers' and parents' approval at the beginning stages; after activities are underway, there may be periods when parents and gatekeepers with conservative attitudes toward girls must be managed. For example, in the Egyptian example given, program managers had to have the trust of the community so that they could negotiate for the continued participation of engaged girls in the education and sports program.

There was much discussion of whether youth centers - often maligned as expensive interventions that exclude females — can be more accommodating of girls. In the Egyptian case, working closely with the Ministry of Youth and Sports and the Ministry of Education, spaces in the village that had been male-dominated were redefined as girls' spaces for certain times of the week, and female staff and mentors were assigned to them.

There was general consensus that adolescent boys need attention and relevant information on sexual and reproductive health, and that the cost issues around condoms are not only social but also material-the cost of condoms is a barrier for otherwise motivated boys (and girls) to protect themselves.

Discussion of programming for boys emphasized that they need positive role models (i.e., male mentors) and support from peers to encourage changed behavior without loss of self-esteem.

A lively discussion centered on when and how to mix the sexes. Should there be invest- ment in programs that initially separate boys and girls and then bring them together at some key moment? Do program models or settings exist that allow for the integration of boys and girls, yet still offer girls a chance to express themselves in light of the power issues that affect them? Do such programs allow boys to openly discuss the burden of traditional masculinity/virility constructs? Learning more about what constitutes an appropriate, safe space for boys and girls, either separately or together, is an area for future research.

\section{Session 7-Safe Livelihoods for Older Adolescents}

This session, chaired by Christine Norton, Senior Adviser, Adolescent Development and Participation, UNICEF, began with observations by Ms. Norton about the importance of livelihoods in fulfilling, respecting, and protecting adolescent rights to health and development. Livelihood programs generally give adolescents the opportunity to have greater control over their futures while allowing them to attain an adequate standard of living, become self-motivated, and achieve mobility with the result that risky behavior is reduced. She challenged planners of second-generation programming for adolescents to consider the necessity of shifting the focus on work from a vocational to a livelihood approach in order to encourage policymakers and programmers to view work, other than hazardous work, as an opportunity and not as a burden and to ensure that both education and work were offered as parts of an integrated program aimed at the total development of adolescent girls and boys. Ms. Norton also discussed the challenge posed by HIV/AIDS and the attempts by programmers to "add on" livelihood components as a means of dealing with risk reduction among young girls in particular. She pointed 
out that in order to ensure the effectiveness and efficiency of programs as part of overall HIV/AIDS prevention efforts, program planners should make certain that livelihood programs were evidence-based and well-targeted.

\section{What Is the Livelihood Approach and Why Is It Important for Adolescent Girls?}

Sajeda Amin of the Population Council opened the session with an overview of adolescent livelihoods. Dr. Amin emphasized that in many settings adolescents spend the majority of their time in some kind of productive work. Although adolescent girls work longer hours than boys, they are less likely to be remunerated for the work they do (in some settings, there is a similar contrast in savings - girls are more likely to save, but have fewer safe places to keep their earnings and assets).

Dr. Amin proposed a view of livelihoods consistent with her own research that opportunities to work for income produce substantial noneconomic benefits, including delayed marriage, improved health behaviors, improved bargaining power with sexual marital partners, and enhanced social mobility and self-esteem.

Yet the word "livelihood" brings to mind economic outcomes only, which generally are at the top of the list of adolescent and parental concerns. However, positive economic outcomes can also mean increased human capital, increased income-earning potential, reduced uncertainty regarding income flow, and increased control over resources. Programs can influence each of these through separate or linked interventions. Life-skills training can increase human capital. Specific economic activities that are well-designed and supported may increase the potential to earn income. The availability of savings and credit opportunities in a collective setting may reduce uncertainty and risk regarding incomegeneration activities. Finally, belonging to a credit union or a girls' or boys' club can increase control over resources.

The livelihood approach recognizes the fluid links between the economic and noneconomic aspects of adolescent lives, and the association of livelihoods with education and reproductive health. In designing livelihood programs, it is essential to collect and weigh information from a number of areas. What are young people doing currently; how do they use their time? What are their aspirations? Is wage or nonwage employment desirable or available for everyone? What are the opportunity structures that affect the ability to work, such as physical safety, transportation, and the means to obtain the entry-level requirements for work?

When discussing the needs of boys and girls, and girls in particular, one must review impediments to access (e.g., there is a fear, expressed by girls and/or their parents, of letting girls travel because their safety and reputations may be compromised). How do social structures affect girls' access and mobility? What is the role of schooling? On the one hand, some schooling may be necessary if girls are to work; on the other, if girls must attend school for seven or eight hours a day, they will be less able to engage in livelihood activities than girls in settings in which school is organized around the economic cycle of the community (e.g., in agrarian communities) or lasts only three or four hours a day.

Dr. Amin emphasized that in many cases adolescents do engage in domestic work, schooling, and income generation. These activities are not incompatible, and sometimes are mutually reinforcing. Planning livelihood programs also requires careful consideration of the diversity of the adolescent population. Because no one formula will reach everyone, it is critical to consider gender, age, marital sta- 
tus, urban/rural residence, and ethnicity in designing a livelihood approach. In addition, the capabilities in different adolescent populations must be assessed, including vocational and technical skills, life skills, basic literacy and numeracy skills, and entrepreneurial or management skills.

Building these skills, either de novo or incrementally, requires tremendous flexibility in program design. Recognizing adolescent capacity may require a different approach than recognizing adult capacity. Dr. Amin gave special attention, for instance, to the role that apprenticeships may have in traditional economic structures. A young worker may not be compensated monetarily, but may gain important skills and access to a market that would otherwise be unavailable.

The program inputs necessary to support young people can include credit, employment opportunities, access to productive assets (e.g., financial assistance to purchase a sewing machine), access to social assets, involvement in networks (e.g., participation in a credit union), and introduction to banks. In addition, programs may need to become more youth-friendly, and barriers to employment may need to be removed.

\section{Kishori Mandal Group, SEWA Project}

Anjali Widge of the Population Council, India, made a presentation on a livelihoods project in India that focuses on building livelihood skills and opportunities for adolescent girls. Taking an evidence-based approach, Council researchers conducted a preliminary review of adolescent livelihood programs in India before designing the project and identifying a partner. Existing research demonstrated that adolescent Indian girls were generally socially and economically disadvantaged and continued to have limited choices because of a lack of eco- nomic independence. The Council decided to work in partnership with the Self Employed Women's Association (SEWA)* because of its experience in the informal sector, its goal of economic empowerment, and its openness to working with young people. Project objectives are to improve the economic and social wellbeing of unmarried and married adolescent girls; their understanding of work roles and how participation in livelihood activities affects self-confidence and negotiating skills; and the ability of girls to influence decisions related to marriage, childbearing, and future livelihood opportunities. The project is also trying to identify effective approaches for expanding safe, appropriate livelihood opportunities for adolescent girls; enhancing the understanding of savings, livelihood training, and group participation as strategies for expanding livelihood opportunities; and supporting SEWA's research capacity.

A pilot project is taking place over a period of three years in two districts of Gujarat State. Approximately 450-900 girls will be covered, and groups of adolescent girls ages 13-19 will be formed in three phases. SEWA introduced the project to the community through village-level meetings, meetings with parents, and meetings with adolescent girls. Project staff decided that only less-educated girls from families of lower socioeconomic status should participate in the groups. The project uses a flexible model, so that girl members can identify the types of activities they will carry out.

In general, girls participating in the project are involved in such routine activities as reading and contributing to Akashganga, a monthly newsletter developed by and for adolescent girls; reading Anusuya, a SEWA magazine for adult women members; and participating in leadership development training and literacy training for those girls not in school.

\footnotetext{
* SEWA is a union that has almost a quarter of a million women members working in the informal sector.
} 
Project activities also include a basic training package of general knowledge and awareness training, and general and adolescent healthrelated training; forestry and nursery training; savings workshops; visits to places of interest and learning; milk cooperative training; and water management training.

The project has worked to establish a loan and scholarship fund to provide girls with access to more formal vocational training such as training in computers or fashion design. In addition to their service activities, project staff intend to document the process of the pilot project with the goal of understanding whether it works, how it works, and whether it can be replicated in other contexts. Staff also intend to conduct an evaluation in order to understand the process of girls' participation in the groups and the impact of the program on their lives. The research design makes use of quantitative and qualitative methodologies to describe the influence livelihood activities have on major life decisions regarding education, work, sexuality, marriage, and childbearing.

\section{Kishori Abhijan Adolescent Girls Adventure}

Lopita Huq of the Bangladesh Institute of Development Studies (BIDS) presented findings on a three-year intervention research project taking place in rural Bangladesh with adolescent girls. Several partners are involved in the program including BIDS (the premiere social science research institute in Bangladesh), BRAC (Bangladesh's largest NGO working in 60,000 villages on children's education, women's credit, and health), the Centre for Mass Education in Science (CMES, a relatively small local NGO specializing in adolescent programming), the Ministry of Women's Affairs, the Population Council, and UNICEF. Kishori Abhijan is a pilot project working to combine life-skills and livelihood training. The community has been involved in the project from the earliest stages. Groups of 20-25 adolescent girls are organized by NGO staff and meet weekly. Peer educators provide skills training and lead group activities and discussions. The girls and NGO workers identify livelihood projects, select members for credit and training, and participate in a savings scheme, which begins on the first day of membership for each girl. The evaluation component of the project uses qualitative and quantitative research methods. Results of a baseline survey indicated that early marriage was generally prevalent within the project area (mean age at marriage was 16-18 years in certain areas); dowry demands were high and rising; the gender gap in education at young ages was disappearing as a result of incentives for girls' schooling, yet girls dropped out of school early because of marriage and subsequent childbirth; and girls had limited mobility and social networks. The project has encountered challenges. For example, there are limited markets for goods because all of the project districts have extremely poor subsistence economies. Similarly, the limited mobility of adolescent girls and women has created time and place constraints for program activities (i.e., they must take place during daylight in the village). The program has had similar administrative constraints owing to the limited mobility of female teachers, which makes it difficult to get qualified teachers to the villages. Negotiating space within villages and challenging traditional values (e.g., incorporating the topic of sexual abuse into the curriculum) have also made programming difficult. Dr. Huq pointed out that because adolescents mature and their lives change, it is difficult to isolate the impact of the program from the impact of schooling and general developmental changes that adolescents experience during this stage in their lives. 
The Workplace as a Venue for Providing Sexual and Reproductive Health Education

Jose Garcia Nuñez of UNFPA gave the final presentation, discussing a study of the sexual and reproductive health needs of young people that took place at youth training and employment programs in five Latin American countries (Bolivia, Colombia, Ecuador, Peru, and Venezuela). Economic participation among young people in this age group is growing quickly. So, too, are training and employment programs. Because offering sexual and reproductive health information and services at the program sites could allow adolescents convenient access to them, a study was conducted in order to propose appropriate strategies for doing so. Research methodology included review of documents, interviews of government authorities, a survey of young people in the five countries, and eight focus groups in each country. The results were varied. One important finding was that young people's visions of the future were uncertain, however, adolescent girls had a clearer vision than boys. Traditional gender roles prevailed among adolescent boys and girls despite new opportunities for employment through training. Communication between adults and young people on issues of sexual and reproductive health was limited. The survey also showed that while knowledge of family planning methods (particularly the pill and the intrauterine device) was high, use of these methods was low as was the ability to acquire contraceptive methods. Dr. Nuñez shared a number of recommendations and challenges regarding reaching adolescents in employment and training programs. Approximately 44 percent of adolescents do not achieve secondary education. Employment facilities offer a practical and acceptable venue for influencing young people's acceptance of information on sexual and reproductive health, therefore it is impor- tant to target sexual and reproductive health training programs to employment sites for young people.

\section{Summary of Discussions}

There was great interest in the livelihoods discussion - centering first on the usefulness of an expanded definition. Many participants emphasized the importance of looking at livelihoods as a gradient of skills and the relationship, particularly for adolescents, between social, productive, and reproductive issues.

Participants seemed especially interested in the notion that some livelihood programs are, in effect, expanded life-skills programs (i.e., because life-skills programs are already familiar, adding a livelihoods component may meet with little resistance). Participants remarked on the extent to which programs had a clear economic content and sought to offer either economic skills or employment opportunities. They also recognized the importance of working with partners outside of the health sector who had an understanding of social and economic development processes as well as a track record, if possible, in specialized areas of micro-finance, savings, and employment training.

Some participants recognized the need to bring programs to where young people are and to directly involve organizations already working with them in programming. The workplace, including training areas, may therefore offer an attractive scenario for sexual and reproductive health programs.

Evaluating adolescent programs with livelihood content was seen as a special challenge. Although such activities may well be designed to have noneconomic benefits, some effort must be made to evaluate the programs' contributions to livelihoods.

Participants emphasized the importance of context-specific interventions, which means considering the age and gender of the groups whose livelihood capabilities or opportunities 
are being expanded as well as their economic situation. In communities that have a strong and long tradition of community-based microfinance and savings schemes, incorporating adolescent livelihood approaches may be more successful than in settings with less such experience and more in-depth poverty.

On the other hand, drawing on the experience in India, there may be many vocational training opportunities that adolescent livelihood programs could link adolescents to, thereby building a social pathway between the opportunity and, in this case, young women. In Uttar Pradesh, for example, a seven-week engagement on a broad reproductive health agenda was carried out before selectively referring girls to vocational training opportunities available through NGOs and government structures. The project also had to underwrite some of the social costs of girls' participation, such as transportation that protected their reputations and safety as they traveled to work.

\section{Session 8-Working with Married Adolescent Girls}

This session, chaired by G. Ogbaselassie of the UNFPA Country Support Team, Harare, Zimbabwe, examined the scope and situation of married adolescent girls, their heightened vulnerability relative to their unmarried peers, and a program that has had success reaching young married girls.

\section{Married Adolescent Girls: The Neglected Majority}

Nicole Haberland, Program Associate from the Population Council's Gender, Family, and Development program, provided an introduction to the issue of married adolescent girls. First, the number of girls married as adolescents is large. A Population Council analysis of DHS data indicated that about half of all girls currently ages 10-19 in developing countries (excluding China) will be married as adolescents. This number varies by country and region, for example, in Nigeria, the proportion of women ages 25-29 who were married before age 18 is 55 percent; in Bangladesh, the proportion is 79 percent. Moreover, in most countries, most sexually active girls are married. In 37 of the 45 countries for which DHS data are available 60 percent or more of sexually active adolescent girls are married.

While marriage offers social respectability, it does not ensure the safety of adolescent girls, who are unconditionally sexually available to their husbands and under pressure to bear children regardless of their own desires or needs. Choosing husbands is usually the job of a girl's parents. In terms of their ability to choose their husbands, the youngest brides have the least choice. For example, among adolescent girls ages 14-15 in Egypt, only 14 percent chose their husbands, whereas among 18-19-year-olds, 26 percent chose their husbands. In addition, spousal differentials in age (e.g., men's mean age at marriage is 7.5 years older than that of their wives in Mali and 4.7 years older in India) exacerbate gender differences within marriage.

Marriage itself can be a lonely and frightening experience for girls. Newly married adolescent girls are often isolated and vulnerable. They are far from their familiar social and familial networks, often have limited mobility, and are in a junior position in their new households.

Married adolescent girls face distinct and severe health risks because of the limited power they have in their sexual/marital partnerships. In general they have higher levels of sexual activity than their unmarried sexually active peers, have little ability to leave an abusive sexual/marital partner, and generally perceive themselves to be at low risk for STIs and HIV/AIDS. Their ability to negotiate condom use and to seek out health information or care 
is also affected by their low status. Finally, once girls are married they are under pressure to prove their fertility, frequently having their first child within 14-24 months after marriage.

Given the danger these conditions pose to the reproductive health of married adolescent girls, it is critical to implement evidence-based approaches to target this vulnerable population. Diagnostic research on the transition to marriage and motherhood is extremely useful in understanding the local context and informing appropriate and effective programs for married adolescent girls. For example, the First Time Parents Project in India found that many young women return to their natal home to deliver their first child, and that there is a desire among some young women and their partners to delay their first birth. Both of these pieces of information had important implications for the project, suggesting places to reach pregnant married adolescents and highlighting opportunities for interventions.

In general, married adolescent girls can be reached at a number of points, with each requiring different program content emphases. For example, the following people could be targeted in the marriage-to-parenthood continuum:

- engaged adolescent girls or couples;

- newly married adolescent girls (with or without their husbands);

- married adolescent girls pregnant for the first time (with or without their husbands);

- new young mothers and their husbands; and

- family members of married adolescent girls (including mothers, mothers-in-law, co-wives, and other senior female family members).

Ms. Haberland described two primary programming approaches for working with this population. The first is to delay girls' aver- age age at marriage through policy advisement and programs that encourage later marriage. Examples include state-level efforts such as in Haryana, India, where the government is providing financial incentives to delay girls' age at marriage.

The second approach is to provide sexual and reproductive health information and services, social support, and social and economic opportunities to engaged and married adolescent girls -including those who are pregnant and those who are already mothers. For example, programs that involve men are a natural link. However, such programs should involve husbands in a way that supports and empowers young women-husbands' involvement should never be mandatory and should only occur with the expressed consent of women. Safe motherhood programs might also be profitably reconfigured to better respond to the needs of young, first-time mothers.

\section{Working with Married Adolescents: A UNFPA Collaborative Experience}

Geeta Sodhi of KIDAVRI India provided insight based on her experiences with the reproductive and sexual health program of Swaasthya, an NGO based in an urban resettlement colony in Delhi, India. The community-based program includes clinical services; information, education, and communication services; social support mechanisms; community-based social marketing strategies; skill-building programs; and projects that provide access to economic resources in the form of micro-credit for married (and, more recently, unmarried) women.

To inform the development of activities for adolescent girls, Swaasthya undertook a needs assessment that revealed that adolescent girls were vulnerable to negative outcomes of sexual activity, namely pregnancy, infections, and sexual coercion and exploitation. A lack of information, skills, and social support contributed to their vulnerability. 
Based on the findings, a set of evidencebased interventions targeted to adolescent girls was introduced to Swaasthya's ongoing community-based program. Adolescent girls now participate in girl groups; receive information and engage in discussions on topics such as health, rights, and adolescent concerns; build skills in decisionmaking, problemsolving, communication, negotiation, relationships, and boundaries; and learn about sexuality and how to prevent sexual abuse.

While none of the interventions was conceived or designed specifically for married adolescent girls, they are among the beneficiaries of Swaasthya's adolescent program and among the beneficiaries of its programs for women. Married girls are accessing clinical services for antenatal care, treatment for reproductive tract infections, fertility regulation, and general health care. They are participating in peer group discussions on health, legal rights, and social issues. They are also accessing micro-credit programs to prepare for delivery and motherhood. Finally, married girls are getting support for dealing with domestic violence and are accessing homebased social marketing outlets for condoms and sanitary napkins.

An evaluation of the scope of married girls' participation in the program and the effects of the interventions on them has yet to be conducted. However, anecdotal evidence suggests noteworthy positive influences. Perhaps one of the most striking effects of the program is the effect it has had on mothers-in-law, who have started to support their daughters-in-law by, for example, encouraging them to access services and supporting their participation in group activities. The positive support of mothers-in-law even extends to gender violence. Mothers-in-law have begun reporting abuse of their daughters-in-law by their sons to paralegal workers. Important strategies that have guided the program include a strong preparatory phase to complete the needs assessment, advocacy activities with gatekeepers, and identification of pre-existing resources.

\section{Learning About Married Adolescents in Senegal}

Carey Meyers presented results from a Population Council study of married adolescent girls in Senegal. Findings from the 1997 Senegal DHS reflect the special needs of this population of adolescent girls. Over half of Senegalese women ages 20-24 are married by age 20, and 91 percent of adolescent girls ages 15-19 who are sexually active are married. In addition, 54 percent of 15-19-yearold girls have ever had a child and 64 percent of 15-19-year-olds who have ever been married have been pregnant at least once. With these data in mind, and with the hope of developing appropriate strategies for a pilot intervention for this population, the Council sought to learn more about the lives of married adolescent girls, and how they differed from those of unmarried girls. (Data on unmarried girls had been collected previously for another Council project.) Using qualitative methods, researchers conducted 187 indepth interviews and recruited 64 participants for focus groups among 13-19-year-old married girls in St. Louis and Louga, semiurban centers in Senegal. The Council also interviewed husbands (in 39 in-depth interviews and 23 focus groups) in order to capture their perspectives on the situation of married adolescent girls.

The findings revealed stark differences in the experiences of married and unmarried girls. Most respondents did not know the age of their spouse; those who did reported sizable age differences. Overall, 46 percent of married girls had one or more children, nearly 70 percent had no direct source of income, about 20 percent engaged in small trade, and 
only 6 percent were allowed to stay in school. The vast majority of married adolescent girls did not choose their husbands, rather, their parents did. Most were informed of the marriage at the last moment, some not until the day of the event. After marriage, the lives of adolescent girls underwent great change. They were no longer free to choose friends, attend school, or go out unless they received permission from one of the female members of the household or were in the company of their husbands. Girls expressed the opinion that they were more mature because they were married. While they appreciated the affection of their husbands and reported that they enjoyed sex, they disliked the subservient role they played in the marriage and the curtailment of their freedom. In terms of reproductive health, most girls wanted to delay childbearing for 2-3 years, and some reported dysmenorrhea and suspected infections. The girls described their husbands as their primary source of reproductive health information, with their mothers-in-law as secondary sources. Girls cited shame, distance, provider attitudes, and inability to pay as reasons for not seeking clinical services. In terms of their economic situation, the majority of the girls reported that their husbands were their only source of income. After a great deal of probing, married adolescent girls suggested participating in small trade or earning money as domestic workers as ways to secure a personal income.

Ms. Meyers summarized the study's findings stating that married adolescent girls differ from their unmarried counterparts with respect to school, mobility, friends, access to information, levels of sexual activity, and childbearing. Married adolescent girls require programmatic attention because of their isolation and early and often unplanned pregnancies. Strategies to reach this vulnerable population might include developing a cadre of married peer educators; involving husbands, mothers, and mothers-in-law; making youth-friendly services more friendly, particularly in the area of safe motherhood programming; and providing married adolescent girls with access to livelihood interventions.

\section{Summary of Discussions}

There are different proportions of married versus unmarried sexually active girls in different regions. For example, in Latin America, married adolescents are less of a priority compared to those who are unmarried, whereas in West Africa the opposite is true. The profile and situation of adolescent girls in various regions, countries, and within countries must be carefully considered so that program planners are clear on whom programs are reaching and how. Participants discussed different program approaches for reaching married girls. Swaasthya, for example, has not targeted married girls explicitly but feels it is meeting their needs. Key participants noted that if a separate program is not initiated, sensitizing staff and adjusting program content to consider the special needs of married adolescents and first-time mothers is critical.

A participant noted that adolescents experience higher levels of morbidity and mortality during pregnancy and labor in the form of severe anemia, pregnancy-induced hypertension (including eclampsia), and obstructed labor due to cephalo-pelvic disproportion. As such, adolescents should receive special antenatal care and should be delivered in a health facility staffed by personnel trained in midwifery. Adolescents should also be provided with counseling services during pregnancy or after delivery on the use of family planning methods, with emphasis on dual protection.

There was debate regarding appropriate HIV prevention messages for married girls. Is it ethical to recommend remaining faithful to her husband as a woman's sole method of 
protection? Most participants thought not. Similarly, the issue of voluntary counseling and testing before marriage was raised.

Participants commented that where the prevalence of HIV/AIDS is high, encouraging couples to participate in voluntary counseling and testing before marriage is important because it enables individuals to learn their HIV status, can encourage behavior change, and can help create a solid base for a safe and satisfying married life. It is true that in the era of HIV/AIDS and high levels of other STIs, the consistent use of condoms should be promoted for dual protection and spacing of pregnancies. However, is recommending condom use within marriage a feasible strategy? There was disagreement among participants, although all agreed that current messages do not take into account the special situation of married girls. Others noted that it is crucial that husbands should also be sensitized and educated to contribute to the reduction of HIV/AIDS and gender-based violence.

\section{Session 9-Preventing HIV/AIDS Among Adolescent Girls and Boys}

This session, chaired by Adjoa Amana of the UNFPA Country Support Team, Ethiopia, explored largely un- or underexamined evidence on HIV risk among subpopulations of adolescents (boys versus girls and unmarried girls versus married girls), and the programming implications for the relative risks. It also addressed a large-scale HIV-prevention intervention and how it has considered the varying needs of different groups of adolescents.

\section{Relative Risks of HIV Among Married and Unmarried Adolescent Girls in Sub-Saharan Africa}

Shelley Clark of the University of Chicago presented her findings on the relative risks of HIV among married and unmarried adolescent girls in sub-Saharan Africa. After observing the rising HIV/AIDS prevalence rates among adolescent girls ages 15-19 and noting that a high proportion of sexual activity among adolescent girls occurs within marriage, Dr. Clark explored the relationship between early marriage and HIV/AIDS. Despite the common belief that sex within marriage is safer than sex before marriage, empirical evidence suggests that it is necessary to question this assumption and look objectively at whether early marriage is contributing to rising rates of HIV infection among adolescent girls.

What are the relative risks of HIV for sexually active married and unmarried girls? There are surprisingly few published studies that compare sexually active adolescents. Those that exist often contain biased results due to their sampling techniques and inclusion criteria. Focusing exclusively on sexually active girls (and omitting virgins presumed to be at minimal risk), Dr. Clark compared sexually active unmarried and married adolescent girls by analyzing DHS data from Burkina Faso, Kenya, and Zambia. She started with an analytical framework, positing that early marriage was associated with certain sociodemographic characteristics that led, in turn, to specific sexual behaviors and HIV risk factors directly affecting HIV status.

Marital status is correlated with a series of sociodemographic characteristics, including age differences, pregnancy intentions, knowledge about HIV, economic opportunities, mobility, access to health care, and social norms about male and female sexual promiscuity. Specifically, the characteristics of married girls that would serve to protect them included their being less likely to engage in sex for money or gifts and to have partners (i.e., their husbands) who were less likely to have more than one partner. In contrast, characteristics that would serve to protect unmar- 
ried girls included a smaller age difference between their partners and them and their being less likely to want to get pregnant. Unmarried girls were also more likely to know a way to avoid AIDS, to have completed primary school, to live in an urban setting, and to know of a source for condoms.

Dr. Clark then examined the association between marital status and several proximate determinants of HIV infection, such as abstinence, frequency of intercourse, number of partners, HIV prevalence among partners, condom use, and the biological rate of transmission. Exploring the link between marriage and HIV risk factors while controlling for sociodemographic characteristics revealed important findings on the effects of early marriage. Marriage appeared to increase adolescent girls' risk of infection with HIV by significantly decreasing their use of condoms at last sex and increasing the likelihood of their having had sex in the last week. Yet, marriage also promoted some protective behaviors: Married adolescent girls were less likely to have had multiple partners. Examining changes in behaviors in response to concerns about HIV/AIDS uncovered further differences. Married girls were less likely to have made any changes in behaviors in response to concerns about HIV/AIDS. They were also significantly less likely to stop having sex, start using condoms, or reduce their number of partners. Married adolescent girls, in fact, were more likely to have only one partner and to ask that partner to be faithful.

Weighing the overall impact of the divergent HIV risk factors and protective strategies of married and unmarried sexually active adolescents is difficult. Yet, a simple analysis of the patterns of unprotected heterosexual activity (the major mode of transmission in sub-Saharan Africa) points toward early marriage as an important factor. Using reported data on frequency of sex and condom use, Dr.
Clark found that 70-85 percent of unprotected sexual activity among adolescent girls in all three countries occurs within marriage. Arguably, unmarried and married adolescents are having sex with very different populations of men, but given that husbands tend to be older than unmarried male partners, it is unclear whether HIV prevalence rates would be higher among the partners of married or unmarried girls in this age group. The study results strongly suggest that early marriage is an important factor in the HIV/AIDS risk equation, and that married and unmarried adolescent girls have very different risk profiles for HIV/AIDS. It is therefore important to develop appropriate messages for married adolescent girls, who still need to be considered in HIV/AIDS prevention strategies.

\section{The loveLife Program: Experiences and Challenges in a "Brand" Approach to HIV Prevention, South Africa}

Angela Stewart-Buchanan of loveLife described the now world-famous loveLife program, based in South Africa. She described the HIV/AIDS scenario in South Africa, where over 5 million people are HIV-positive. She emphasized that the importance of moving beyond information to behavior change is evident in the country, where 98 percent of the adult population are aware of HIV, but only 10 percent use condoms. HIV, tragically, is infecting younger and younger people, and young women are becoming infected at a much higher rate than young men, with some of the highest rates of infection emerging among girls ages 15-20 and young men ages 20-25. Twelve million South Africans are under the age of 15 , and they are becoming sexually active just as the HIV epidemic is peaking. Chances are that half of them will become HIV-positive. A number of factors contribute to why young South Africans are having early and unprotected sex. Sex is often 
coerced - 39 percent of girls reported forced sex. Young boys experience pressure from peers to exert their manliness. In addition, in such a poor country there is much transactional sex, that is, the exchange of sex for goods, money, and favors. There are also high levels of violence against women, often in the context of intimate relationships, which both increase and exploit girls' and women's low self-esteem.

loveLife's target population is 12-17year-old adolescents, whom the program tries to reach before they become sexually active. More than an information program, loveLife is a lifestyle "brand" for young South Africans that makes use of traditional marketing techniques to promote healthy living and positive sexuality. Its goal is to halve the rate of new HIV infections, STIs, and pregnancies among 15-20-year-olds within a five-year period (i.e., by the end of 2005).

loveLife uses a three-point strategy that includes high-powered multimedia communication, outreach and delivery services, and research. The starting point in combating HIV is to get people in South Africa talking more openly about the AIDS epidemic and sexual behavior in general. The program endeavors to teach adolescents how to assert the importance of setting and observing sexual limits and delaying first intercourse. For those who are sexually active, it urges delaying the next sexual encounter, reducing the number of sexual partners, and increasing condom use.

loveLife seeks to be a positive part of young people's lives, and not simply an information campaign, such that they will internalize its messages and integrate its approach into their everyday lives. The service-delivery program includes free help lines, which receive more than 50,000 calls per month; multipurpose recreational youth centers that combine clinical services, computer training, sports and recreation (including basketball), and personal motivation; youth-friendly clin- ics that work with government clinics to make them more accessible to young people; franchises, with 106 community-based organizations that have adopted the loveLife messaging approach; outreach through two radio broadcast units and a mobile sexual health education center and clinic housed in a railroad car that travels throughout the country on the national rail network; the loveLife games, which are the largest inter-school sports development program in South Africa; partnering with schools; and the groundBREAKER program, which takes unemployed 18-25-year-olds off the streets and involves them in a supervised program of community mobilization linked to all loveLife programs.

loveLife's media activities are what first brought it to public attention both in South Africa and the wider world. Advertisement placement is intensive and includes television, radio, taxis, billboards, and water tanks.

Advertisements are broadcast on the radio in 11 languages and printed in newspapers and magazines. Mindful of the role of adult leaders' influence on young people, the program's messages encourage parents to talk about sex with their children ("Love them enough to talk about sex") and have benefited from public support from leaders such as Archbishop Desmond Tutu and Nelson Mandela.

loveLife has carried out some evaluation of its programs, through self-reported behavior change research among its target audience of 12-17-year-olds, and has identified segments of the youth audience it reaches most effectively (e.g., by age, gender, and schooling and marital status). Among 62 percent of young people who report having heard of loveLife, 78 percent reported that it made them more aware of the risks of unprotected sex, and 65 percent reported the program had made them delay or abstain from sex. Most encouraging is change among sexually active 
young people -78 percent say their interaction with loveLife is responsible for their using condoms consistently during sex. Obviously self-reported behavior should be interpreted with caution, but even if the findings were halved, it still suggests that fundamental change is occurring.

Though expensive, the program is powerful, and in the context of saving lives, it can be viewed as being cost-effective. The current annual budget is R200 million (approximately US\$23 million). In order to mount a program of this range and vision, many partnerships are required, including those with the government, private foundations, and corporations (who donate resources and money).

\section{Summary of Discussions}

There was animated discussion about the feasibility of workshop participants advocating for later marriage-based both on rights/demographic factors and increasing evidence that marriage does not provide a safe haven from poor reproductive health, including HIV. Much attention was given to the need to understand more about possibilities for negotiation within marriage, especially for the youngest married women under pressure to become pregnant. There was also great concern about strategies that would be safe and feasible for married or unmarried adolescent girls and how best to intervene with them and their partners. There is a continuing debate about whether program staff could recommend the use of condoms within marriage and under what circumstances. Much concern was expressed about actions that are ethical and feasible in situations where the partner of a married adolescent girl is HIV-positive or has had-or currently has-outside partners.

Also discussed were the best ways that antenatal, pregnancy care, and after-care programs could give differential attention to married adolescent girls and ways programs could draw in partners and other family members.

There was much enthusiasm for the loveLife program, particularly as it has reached national scale. One participant noted that within South Africa, if present trends among girls currently $10-14$ years old continue, within some communities as many as half might be infected with HIV by age 19. It was thus emphasized that such energetic programs need to give special attention to reaching younger adolescents, particularly girls, with information and protective strategies.

The discussion also centered around youth centers and how loveLife continues to attract substantial numbers of both boys and girls to youth centers first by offering such activities as basketball and netball and access to computers, music, and entertainment and then giving them the opportunity to enroll in sexual health courses. 
12 Population Council

One Dag Hammarskjold Plaza New York, New York 10017 USA
(6) UNFPA

$\circ \circ \circ$

United Nations Population Fund 220 East 42nd Street,

New York, NY 10017, U.S.A. 